\title{
Empleo racional de los cementos para los diferentes tipos de obras
}

Prof. Dr. JOSE CALLEJA

IETCC

MADRID - España

\section{índice}

Págìna

1. $\quad \begin{array}{lllllllllllllll} & & \end{array}$

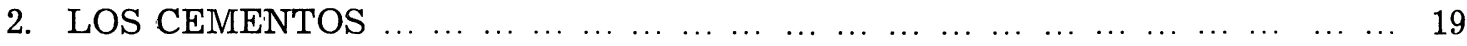

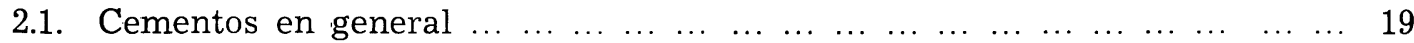

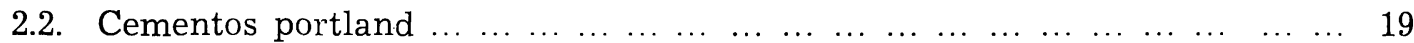

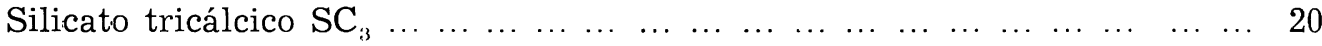

Silicato bicálcico $\begin{array}{llllllllllllllllllll}\mathrm{SC}_{2} & \ldots & \ldots & \ldots & \ldots & \ldots & \ldots & \ldots & \ldots & \ldots & \ldots & \ldots & \ldots & \ldots & \ldots & \ldots & \ldots & \ldots & 21\end{array}$

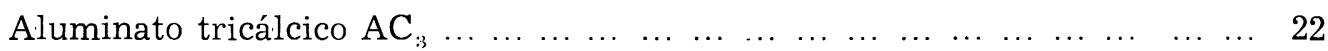

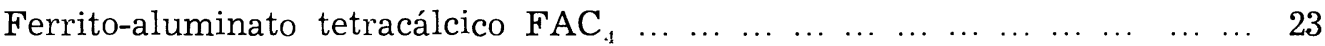

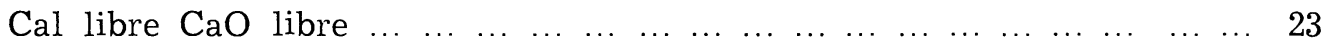

Magnesia
$\mathrm{MgO}$

Alcalis $\mathrm{Na}_{2} \mathrm{O} \quad \mathrm{y}^{\mathrm{K}_{2} \mathrm{O}}$

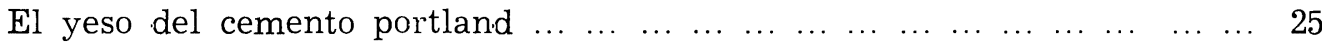

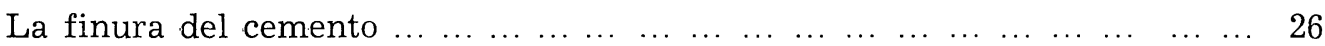

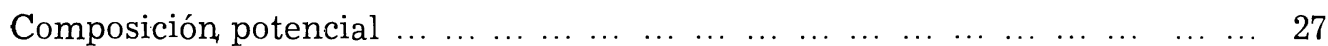

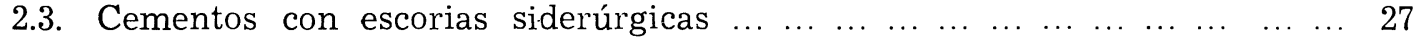

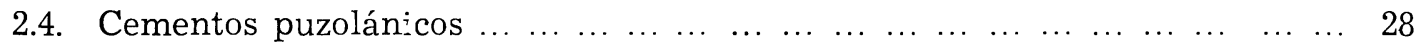

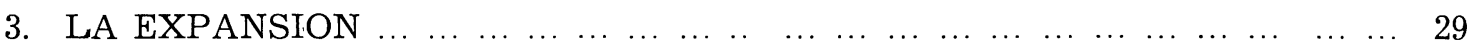

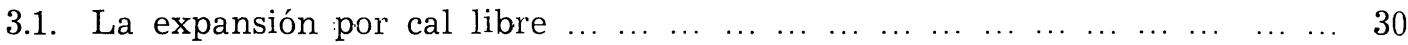

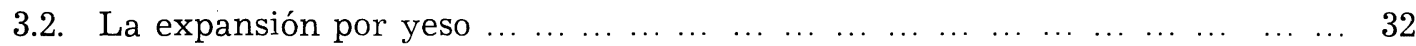

3.3. El ataque por $\operatorname{sulfatos}\left[\begin{array}{llllllllllllllllllll} & \ldots & \ldots & \ldots & \ldots & \ldots & \ldots & \ldots & \ldots & \ldots & \ldots & \ldots & \ldots & \ldots & \ldots & \ldots & \ldots & 33\end{array}\right.$

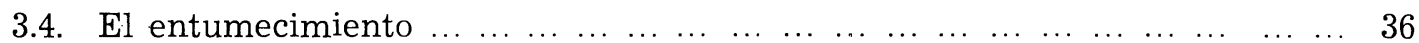

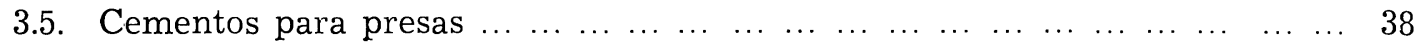

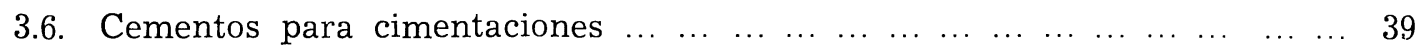

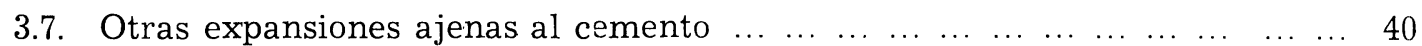

3.7.1. Reacción árido-álcalis $\ldots \ldots \ldots$ maduras $\ldots \ldots \ldots \ldots \ldots \ldots$

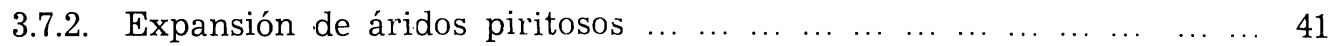

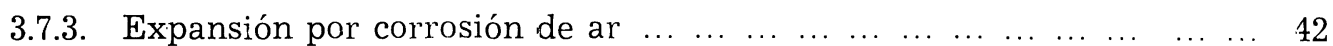

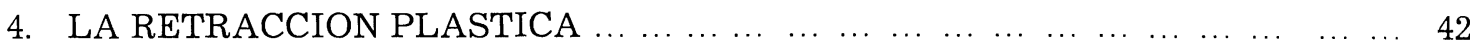

5. $\quad$ FINAL $\ldots \begin{array}{llllllllllllllllllllllllll} & \ldots & \ldots & \ldots & \ldots & \ldots & \ldots & \ldots & \ldots & \ldots & \ldots & \ldots & \ldots & \ldots & \ldots & \ldots & \ldots & \ldots & \ldots & \ldots & \ldots & \ldots & \ldots & \ldots & 45\end{array}$

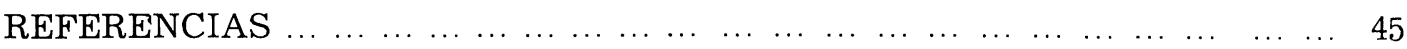

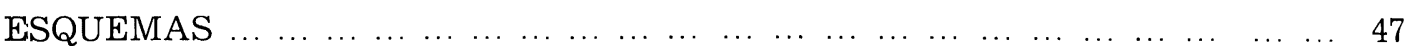

Materiales de Construccion N. ${ }^{\circ} 180-1980$ 


\section{Empleo racional de los cementos para los diferentes tipos de obras}

Prof. Dr. JOSE CALLEJA

IETCC

MiNRIJ. - España

\section{INTRODUCCION}

La tesis del contenido de esta conferencia podría resumirse en los siguientes cinco puntos:

1. Prácticamente todos los países del mundo que fabrican y utilizan cemento, producen y emplean cementos de distintos tipos, clases y categorías, en relación con las características físicas, químicas y mecánico-resistentes de los mismos.

2. Todas las obras, estructuras y elementos estructurales de hormigón imponen, en función de sus particularidades intrínsecas - propiedades y características - y. extrínsecas - funcionalidad de servicio en las circunstancias ambientales de cada caso-, una serie de condiciones al material hormigón, ya sea masivo, armado o pretensado.

3. Estas condiciones se refieren, fundamentalmente, a tres parámetros: resistencia mecánica, estabilidad y resistencia química. El conjunto de los tres constituye lo que en términos generales y amplios se puede llamar DURABILIDAD de la obra, esto es, su permanencia en servicio a lo largo del tiempo, y con la garantía de un margen de seguridad suficientemente amplio en todo momento, y en todas las circunstancias reales previsibles de dicho servicio.

4." Para conseguir la calidad y el comportamiento óptimos de las obras, y con ello la máxima durabilidad de las mismas, es preciso que los componentes del hormigón, sus proporciones y la tecnología del material sean los más adecuados.

5." Por lo que se refiere en particular al más activo y delicado de los materiales del hormigón, el cemento, éste puede y debe ser el más idóneo en cuanto a tipo, clase y categoría, así como en cuanto a dosificación y modo de empleo, para conseguir los hormigones y las obras más durables en cualquier caso.

Por todo ello, en esta exposición se va a tratar de dar una visión de las características, de las propiedades y de los comportamientos más destacados de los cementos, en los más variados aspectos de interés para el ingeniero proyectista y constructor. Por consiguiente, también se va a tratar de relacionar estas propiedades con los principales problemas que

\footnotetext{
* Conferencia pronunciada en las SEgUNDAS JORNADAS INTERNACIONALES DE LA CONSTRUCCION, en el marco de la EXPO-CONSTRUCCION 80, organizada por el CENTRO DE INGENIEROS DE ROSARIO (Argentina), en Buenos Aires, 17-19 de Diciembre de 1980.
} 
pueden surgir en la utilización práctica, adecuada o no, de los cementos en los principales tipos de obras.

Sentado esto, cabe precisar que la resistencia mecánica del hormigón se suele tomar como la característica, si no única, sí la más importante, con mucho, sobre las demás, a la hora de pensar en un hormigón estructural durable.

Esto sería bueno si no hubiese que contar con la estabilidad del hormigón -en términos de expansión, retracción, fisuración micro y macro (agrietamiento), fluencia, etc.-, y con la resistencia química del hormigón -en términos de ataques al mismo por agentes agresivos del medio ambiente: agua de mar, yeso de los suelos y terrenos, atmósferas contaminadas, desagües industriales, etc.-.

Si ambas, estabilidad y resistencia química, o una sola de ellas, llegan a ser insuficientes en algún momento, lo primero que se afecta negativamente es la resistencia mecánica. Al existir de hecho y siempre esta interdependencia, a la hora de diseñar un hormigón durable hay que pensar, no sólo en la resistencia mecánica del mismo a corto, medio y largo plazo - la cual va a ser de seguro más que suficiente (por razones de proyecto)-, sino más bien y antes, en las medidas necesarias para mantener esa resistencia a lo largo de la vida útil previsible para la obra, frente a posibles faltas de estabilidad del hormigón, o a posibles acciones químicas, internas o externas, actuando desfavorablemente sobre el mismo.

Esto requiere que los materiales del hormigón -y el propio hormigón como conjunto-. cumplan con una serie de exigencias mínimas que se establecen en las Normas, así como que se utilicen en cada caso, y en la forma más idónea, los materiales más adecuados, lo cual suele ser objeto de Recomendaciones, Guías y Códigos "de buena práctica", los cuales deben ser bien conocidos y tenidos en cuenta.

Una vez más, y por lo que atañe a los cementos contemplados en las Normas vigentes en España, por poner el ejemplo concreto que lógicamente tengo más a mano, uno de tales Códigos (1) es el que recientemente se ha publicado, en relación con dichas Normas españolas (2).

Hay casos en los que el planteamiento, el raciocinio y la conclusión sobre el cemento o los cementos que conviene utilizar con ventaja en determinadas circunstancias son evidentes e inmediatos. Por ejemplo: en presencia de áridos reactivos frente a álcalis, hay que emplear cementos con contenido bajo de álcalis ; frente a posibles ataques por sulfatos, hay que usar cementos con bajo contenido de aluminatos ; para obras de hormigón predominantemente masivo, en las que puedan esperarse fuertes retracciones térmicas y/o hidráulicas con las consiguientes posibles fisuraciones y agrietamientos, es preciso utilizar cementos de bajo calor de hidratación y de escasa retracción y, tal vez, preferentemente no de ti. po portland, etc.

Pero no es oro todo lo que reluce. Se quiere decir, usando de la redundancia, que estas "reglas de oro" no siempre dan resultado o, mejor, no siempre basta con aplicarlas en exclusiva para obtener el resultado apetecido. Porque éste casi nunca depende exclusivamente de la aplicación, sin más, de dichas reglas.

En discernir los matices y en la correcta aplicación de ese discernimiento se basa la buena - la mejor- práctica, y de ello depende el éxito técnico e incluso económico - a corto y/o largo plazo- de las obras bien realizadas.

La elección acertada de un material para una finalidad dada exige el conocimiento del 
material en sí, y el del comportamiento del mismo -en comparación con otros materiales alternativos-, en las condiciones genéricas y específicas impuestas por la finalidad en cada caso. Esto es particularmente válido para la elección de un determinado tipo. clase y categoría de cemento para ser utilizado en un determinado tipo de estructura o de obra. A ello va dirigida, principalmente, la exposición que sigue y los ejemplos prácticos de casos reales que en ella se tratan.

\section{LOS CEMENTOS}

El que expone que no es Ingeniero Civil, sino Químico, se disculpa de ant€mano ante los oyentes por tener que hacer uso de la Química —en este caso de la Química del Cementoy de las características físicas y mecánicas del material, para fundamentar sobre ellas la más correcta y eficaz utilización tecnológica de los cementos, en los aspectos de resistミncia mecánica, estabilidad y resistencia química (DURABILIDAD) de los hormigones.

\subsection{Cementos en general}

Reconocen las Normas diversos tipos, clases y categorías resistentes de cementos: los portland "puros", constituidos exclusivamente por clínker y yeso, y los que, además, contienen adiciones - generalmente activas en una $u$ otra forma (escorias siderúrg: ass, puzolanas naturales o cenizas volantes de central termoeléctrica) - en distintas proporciones.

Una panorámica gráfica de todos estos cementos de acuerdo con cualquier norma, pero referida en este caso por vía de ejemplo a la española en vigor, es la que se presenta en los esquemas de las figuras correspondientes 1 y 2 . Comparados desde el punto de vista de la resistencia mecánica los cementos de calidad 550 - kilopondios de resistencia a compresión a 28 días en mortero normal ISO-RILEM-CEMBUREAU_pueden asimilarse a los cementos de endurecimiento rápido y/o de altas resistencias iniciales de otras normas. Los cementos de calidad 350 equivalen a los de endurecimiento normal y los de categoría 450 ocupan una posición intermedia, acercándose más a uno u otro de los anteriores, según que por su resistencia real se sitúen en la parte superior o en la inferior del intervalo $450-550$.

\subsection{Cementos portland}

Los cementos portland, constituidos exclusivamente a base de clínker (con una pequeña proporción - poco variable de unos a otros--..de retardador, que generalmente es una forma de sulfato cálcico - yeso- o una mezcla de ellas) deben sus propiedades y su comportamiento, tanto en cuanto a resistencias como en cuanto a estabilidad y a durabilidad, a la constitución química del clínker y a la finura de molido.

Los constituyentes del clínker, creados en los hornos de las fábricas de cemento a partir de los componentes de las materias primas calizas y arcillosas (sílice, alúmina, óxido férrico, cal, magnesia y álcalis, principalmente), son los silicatos, los aluminatos y los ferritos cálcicos, la cal libre (no combinada) y los compuestos magnés: cos y alcalinos.

Una visión de conjunto, tanto de los componentes como de los constituyentes del clínker y del cemento, es la dada en el esquema 3. En él se puede apreciar que los silicatos son dos, el tricálcico y el bicálcico. que se designan por $\mathrm{SC}_{3}$ y $\mathrm{SC}_{2}$; que el aluminato es uno so- 
lo, en general: el tricálcico que se designa por $\mathrm{AC}_{3}$; y que el ferrito es también uno solo, en general aunque en realidad es un ferrito-aluminato complejo: el tetracálcico, que se designa por $\mathrm{FAC}_{4}$.

Las proporciones medias relativas de estos constituyentes del clínker suelen ser las indicadas en el esquema 4, según el cual en el resto se incluyen la cal libre, la magnesia y los compuestos alcalinos, principalmente, en las proporciones indicadas. Los campos de variación, a su vez, suelen ser los indicados con amplitud en el esquema 5.

En cuanto al cemento portland, está formado, en promedio, por 95 por ciento de clínker y 5 por ciento de retardador (yeso dihidrato y/o hemihidrato y/o anhidrita), de tal manera que su constitución puede corresponder a la expresada en el esquema 6.

La hidratación del cemento, es decir, su reacc:ón y combinación con el agua, da lugar a los procesos sucesivos del fraguado y del endurecimiento, en los que se producen las acciones y los efectos, tanto favorables como desfaverables desde el punto de vista tecnológico del empleo del conglomerante. La hidratación del cemento es, en conjunto, muy complicada, pero en todo caso es la suma o resultante de las hidrataciones individuales de sus constituyentes anhidros. De la complejidad del proceso da idea el esquema 7.

En el aspecto tecnológico de la hidratación de los cementos, y aparte del desarrollo de las resistencias mecánicas, hay que tener en cuenta una serie de parámetros, de los cuales los más importantes son los indicados en el esquema 8.

La participación de cada uno de los constituyentes del cemento, a través de su hidratación, en todos estos parámetros, incluido el relativo a la evolución de las resistencias mecánicas con el tiempo, es la que se indica a continuación:

\section{Silicato tricálcico $\mathbf{S C}_{3}$}

Desarrolla un gran calor (calor de hidratacıón), así como elevadas resistencias a corto plazo, y libera abundante cantidad de cal (cal de hidrólisis).

Por la primera circunstancia, los cementos ricos en silicato tricálcico - del orden dei 45 al 60 por ciento- desprenden gran cantidad de calor. En consecuencia, particularmente cuando se emplean con dosificaciones altas - por ejemplo, superiores a $300 \mathrm{~kg} / \mathrm{m}^{3}$ - o en grandes masas de hormigón con pequeña relación de superficie a volumen, esas masas de hormigón se calientan demasiado y, sometidas a un choque térmico por enfriamiento - por ejemplo, durante el transcurso de una noche fría-, se pueden contraer dando lugar a fisuraciones y agrietamientos por causa de una retracción térmica.

Por otra parte, el fuerte calentamiento de los hormigones provoca en ellos una autodesecación, si no se evita con un curado húmedo adecuado. La desecación puede producir una retracción hidráulica que sumada a la térmıca puede intensificar la fisuración y el agrietamiento.

Por estas razones los cementos ricos en silicato tricálcico no se suelen ni deben, ni pueden emplear en el hormigón de presas. Muy al contrario, las normas de cemento o las recomendaciones e instrucciones para el empleo racional de éstos suelen limitar el contenido de silicato tricálcico de los cementos portland destinados a tal empleo.

En cuanto a las resistencias elevadas a corto plazo, los cementos con alto contenido de silicato tricálcico — del orden del 50 al 60 por ciento- forman parte de los llamados de 
endurecimiento rápido o de altas resistencias iniciales, los cuales son aptos para la prefa-: bricación en hormigón - sobre todo si en ésta no se emplean tratamientos térmicos aceleradores del desarrollo de la resistencia-, y para aquellas obras que requieran en sus estructuras un descimbrado o un desencofrado rápidos.

En cambio, tanto por sus elevadas resistencias iniciales y a corto plazo, como por su gran calor de hidratación, los cementos ricos en silicato tricálcico son especialmente aptos para el hormigonado en países, climas y épocas fríos y húmedos.

En lo relativo a la abundante cal liberada en la hidratación del silicato tricálcico, esta cal es sensible al ataque y disolución por aguas ácidas, puras y carbónicas agresivas. Por este motivo, la durabilidad -en este caso resistencia química - de los hormigones hechos con cementos ricos en silicato tricálcico y que hayan de estar sumergidos o en contacto intermitente con tales aguas, máxime si fluyen y se renuevan, ha de ser lógicamente menor que la de los mismos hormigones hechos cor cementos de contenido en silicato tricálcico menor.

En contrapartida, esa abundante cal liberada en la hidratación confiere a los hormigones un alto grado de basicidad ( $\mathrm{pH} 12$ a 13) o alcalinidad, así como una gran reserva alcalina, circunstancias ambas que son favorables para evitar o retardar la corrosión de las armaduras en el caso de los hormigones armados y pretensados. En consecuencia, para estos últimos son aconsejables los cementos de alto contenido de silicato tricálcico, aparte de las razones de índole resistente.

Como es fácil ver por lo expuesto, hay una especie de incompatibilidad entre las resistencias elevadas - particularmente a plazos cortos - y la acción protectora sobre las armaduras, por una parte, y la retracción -fisuración y agrietamiento- y la durabilidad frente a las aguas puras, carbónicas agresivas y ácidas, por otra parte. En cada caso habrá que elegir cementos de alto o de bajo contenido de silicato tricálcico, según la circunstancia predominante. Llevado al terreno práctico, quiere esto decir que habrá que optar por el empleo de un cemento de contenido elevado de $\mathrm{SC}_{33}$, de contenido medio o de bajo contenido, según el tipo de hormigón y obra: el primero está indicado para prefabricación y pretensado, así como para hormigonar en tiempo o climas fríos; el segundo para hormigón estructural ordinario, y el tercero para hormigones en grandes masas en que interese poca retracción y escaso calor de hidratación, así como para trabajos de albañilería (aunque para esto último hay cementos distintos, especialmente aptos).

Un ejemplo aleccionador a este respecto lo da el caso de un constructor que dispuso el empleo de un cemento de bajo contenido de silicato tricálcico, esto es, de baja categoría cesistente y, por lo tanto, de menor precio, para un mortero de junta de ladrillos en un muro de fábrica. Por circunstancias que no son del caso, la obra se llevó a cabo con un cemento de resistencias mucho más elevadas a cualquier plazo. Al poco tiempo el muro se rajó de arriba abajo por retracción, en varios sitios. La lección del caso es que no siempre lo mejor (mejor ¿para qué?) es bueno. La anécdota va más allá, pues el fabricante, que había vendido el cemento "mejor" al precio más bajo del "peor", no comprendía el enfado y las quejas del constructor quien, según él, debía estarle agradecido (claro está que desconocía el empleo del cemento vendido y sus resultados lógicos).

\section{Silicato bicálcico $\mathbf{S C}_{2}$}

Desarrolla mucho menos calor de hidratación que el tricálcico, libera bastante menor cantided de cal, y da menores resistencias a corto plazo, aun cuando las resistencias a plazos más largos son casi tan elevadas como las que proporciona el silicato tricálcico. Es el 
constituyente principal de los cementos portland llamados de endurecimiento normal o lento, y de los cementos portland más "fríos"

Por otra parte, en el cemento portland los silicatos tricálcico y bicálcico se pueden considerar como valores o parámetros "conjugados", cuya suma es constante -aproximadamente el 70 por ciento de la composición del cemento-, de tal manera que el aumento de uno implica la correspondiente disminución del otro.

Así se comprende que las indicaciones y contraindicaciones del empleo de los cementos ricos en $\mathrm{SC}_{3}$ (60 por ciento) -o pobres en $\mathrm{SC}_{2}$ (20 por ciento) - y pobres en $\mathrm{SC}_{3}$ (30 por ciento) -0 ricos en $\mathrm{SC}_{2}$ (40 por ciento)- se entrecrucen, deduciéndose de ello las correspondientes consecuencias prácticas en cađa caso.

Esto es lo que, de un modo general, pone de manifiesto el esquema 9. Y en cuanto al distinto desarrollo de las resistencias de los cementos ricos en silicato tricálcico y pobres en silicato bicálcico o recíprocamente, el gráfico esquemático 10 es suficientemente indicativo. Consecuentemente con estos hechos, el esquema 11 pone de relieve las distintas cantidades de cal de hidrólisis que, $\mathrm{mol} \mathrm{a} \mathrm{mol,} \mathrm{o} \mathrm{peso} \mathrm{a} \mathrm{peso,} \mathrm{liberan} \mathrm{los} \mathrm{silicatos} \mathrm{tricálcico}$ y bicálcico, lo cual se relaciona tanto con las resistencias y con el calor de hidratación, como con la resistencia química y la protección a las armaduras del hormigón en la forma que ha quedado expuesto.

\section{Aluminato tricálcico $\mathbf{A C}_{3}$}

Posee una gran velocidad de hidratación, en la cual desarrolla mucho calor -es el constituyente que más calor desprende-, colabora moderadamente a las resistencias a muy corto plazo, y no solamente no libera cal en su hidratación, sino que, por el contrario, puede fijar en una cierta proporción la cal liberada por los dos silicatos.

Es el constituyente causante del fraguado rápido del cemento, y el que exige que, por lo tanto, se añada yeso -en general un retardador consistente en una o varias formas de sulfato cálcico- para retardar, regular y normalizar el fraguado.

Es muy sensible a los sulfatos en general -aguas selenitosas, terrenos yesíferos y agua de mar-, con los que reacciona dando lugar a productos expansivos —ettringita: sal de CANDLOT o "bacilo del cemento"-, los cuales provocan la destrucción del hormigón.

El aluminato tricálcico abunda más en los cementos portland blancos que en los grises, y su hidratación en presencia de un exceso de yeso puede tener un carácter expansivo diferido.

En resumen, las características más destacadas del $\mathrm{AC}_{\text {:3 }}$ son un gran calor de hidratación, su tendencia a la expansión en determinadas circunstancias, y su debilidad frente a eventuales ataques químicos por sulfatos en general y por los medios y ambientes que los contienen -aguas y terrenos selenitosos, agua de mar, etc.-

Por lo tanto, los cementos ricos en $\mathrm{AC}_{: 3}$ no se deben emplear en obras, estructuras o elementos de hormigón que hayan de estar en contacto con tales medios. Por el contrario. en semejantes casos se deben emplear cementos de bajo contenido de $\mathrm{AC}_{i 3}$, llamados resistentes a sulfatos, para los que las normas estipulan contenidos máximos admisibles de aluminato tricálcico y, de alguna manera, también de aluminato tricálcico y de ferritoaluminato tetracálcico en conjunto. En el caso de las normas españolas estas estipulaciones son de 5 por ciento para $\mathrm{AC}_{33}$ y de 22 por ciento para $\mathrm{AC}_{: 3}+\mathrm{FAC}_{4}$, como máximo. 


\section{Ferrito-aluminato tetracálcico $\mathbf{F A C}_{4}$}

Se caracteriza por una lenta velocidad de hidratación, en la que desarrolla poco calor; por una escasísima contribución a las resistencias mecánicas a cualquier edad, y por una buena resistencia química frente a los ataques químicos de los sulfatos.

Sus propiedades se contraponen, en cierto modo, a las del aluminato tricálcico. El FAC 4 escasea o prácticamente no existe en los cementos portland blancos y, por el contrario, abunda en los cementos portland llamados de tipo férrico, en los llamados cementos de moderado o bajo calor de hidratación, en los cementos resistentes o moderadamente resistentes a los sulfatos, y en los cementos fríos. si al mismo tiempo son ricos en $\mathrm{SC}_{2}$ y pobres en $\mathrm{SC}_{3}$ (véase Silicato bicálcico).

Así como los dos silicatos eran constituyentes "conjugados", cuya suma de tantos por ciento en el camento se puede considerar como aproximadamente constante, lo mismo sucede con el $\mathrm{AC}_{3}$ y el $\mathrm{FAC}_{4}$ — cuya suma asciende al 20, ó 25 por ciento de la composición total del cemento-, de modo que un alto valor de uno de ellos lleva aparejado un valor bajo del otro.

Esto explica el hecho de que las indicaciones y contraindicaciones de empleo de los cementos ricos en $\mathrm{AC}_{3}$ (15 por ciento) -o pobres en $\mathrm{FAC}_{4}$ (5 por ciento)-, y pobres en $\mathrm{AC}_{3}$ (5 por ciento) $\longrightarrow$ o ricos en $\mathrm{FAC}_{4}$ (20 por ciento)-, también se entrecrucen, de lo cual se derivan las conclusiones de tipo práctico que pone de manifiesto el esquema 12 .

Los cementos ricos en $\mathrm{FAC}_{4}-\mathrm{y}$ simultáneamente en $\mathrm{SC}_{2}$ - son aptos para hormigonar en épocas o climas muy cálidos, o para ejecutar obras con grandes masas de hormigón, tales como las presas. Los cementos considerados en las normas como "de bajo calor de hidratación" son los que desprenden un calor no superior a un determinado número de calorías/gramo a 7 y a 28 días.

Los cementos ricos en $\mathrm{FAC}_{4}$ son los típicos portland resistentes a sulfatos - con limitaciones de $\mathrm{AC}_{3}$ y de $\mathrm{AC}_{3}+\mathrm{FAC}_{4}$ análogas a las indicadas antes-, y que confieren mayor durabilidad a los hormigones en medios yesíferos y sulfatados en general. Regiones yesíferas por excelencia son la de París en Francia, la del sur y oeste de los Urales en la Unión Soviética, y la de la mitad oriental de la España Peninsular, según el meridiano de Madrid - por otra parte, la España Calcárea, frente a la España Silícica que es la mitad occidental, según dicho meridiano-.

La compleja hidratación de los aluminatos y ferritos cálcicos del c:mento queda de ma. nifiesio en el esquema 13, el cual hay que considerar como parcial y, por lo tanto, incompleto, por cuanto que ni los procesos indicados son todos los que pueden tener lugar, ni sa paran en los compuestos hidratados que se indican, pues su evolución puede continuar, y de hecho continúa de formas muy diversas, según las circunstancias.

Una visión de conjunto de las características más salientes de los silicatos y aluminatos cálcicos del clínker y de los cementos, tal como queda expuesto, la da el esquema 14.

Y una visión particularizada al caso del desarrollo de las resistencias mecánicas a lo largo del tiempo por parte de los mencionados silicatos y aluminatos cálcicos la da asimismo el esquema 15.

\section{Cal libre CaO libre}

La cal libre es un constituyente frecuente, pero no deseable del cemento portland. Su exis- 
tencia es debida a defectos de fabricación que se pueden atribuir a diversas causas que actúan aislada o conjuntamente.

La hidratación de la cal libre es expansıva, pudiendo dar lugar a cuarteamientos superficiales del hormigón, e incluso al debilitamiento y a la destrucción de éste.

Como la cal liberada por hidrólisis en la hidratación de los silicatos, la cal libre hidratada es atacable por las aguas puras, ácidas y carbónicas agresivas.

Por los hechos expuestos, los cementos con abundante cal libre, ni son estables ni son durables. En otro aspecto, la cal libre, junto con la cedida por los silicatos, eleva la reserva alcalina de los hormigones, con lo cual contribuye a la protección de sus armaduras contra la corrosión.

No existen, en general, en las normas para cemento, prescripciones limitativas de la cal libre en los mismos, aunque existen métodos para determinarla. En lugar de tales limitaciones se suelen estipular otras relativas a la propia expansión, de acuerdo con diferentes procedimientos para detectarla y medirla - entre ellos, el método de las tortas o galletas. el de las agujas LE CHATELIER y el del autoclave-. Pero de ésto se tratará en particular más adelante.

\section{Magnesia MgO}

La magnesia, como la cal libre, puede ser expansiva, aunque, en general, a muy largo plazo. En tales condiciones la expansión del cemento debida a la magnesia es muy nociva por sus efectos. Por este motivo las normas para cementos suelen fijar un máximo para el contenido admisible de magnesia en los cementos portland, el cual es, en general y en promedio, del 5 por ciento.

Al contrario de lo que sucede con la cal libre, además de la limitación del contenido de magnesia las normas fijan también un máximo para la expansión, el cual se cuantifica en el caso de los ensayos de las agujas LE CHATELIER y en el del autoclave.

Este último ensayo pone de manifiesto la expansión por todos los conceptos, si bien fue concebido para poner de relieve la expansión lenta y retardada de la magnesia, y por unas causas y con una finalidad, en su época, que valdría la pena comentar en coloquio, porque es algo que, dentro de la química y de la tecnología del cemento, ya constituye historia clásica, y también anecdótica.

El ensayo del autoclave es un método muy drástico, cuyas condiciones de trabajo se alejan mucho de la realidad, y que exige muy buen criterio a la hora de interpretar y valorar sus resultados. Por de pronto; los resultados del ensayo de autoclave no guardan relación con los de otros métodos paŕa determinar la expansión, y tampoco guardan relación siempre con el comportamiento, expansivo o no, de los cementos en la práctica. Pero, se repite, sobre este tema se volverá más adelante.

\section{Alcalis $\mathrm{Na}_{2} \mathrm{O}$ y $\mathrm{K}_{2} \mathrm{O}$}

Los álcalis del cemento se encuentran, o bien combinados con el $\mathrm{AC}_{33}$ y el $\mathrm{SC}_{2}$, o bien en forma de sulfatos —-sódico y potásico-, o de ambas maneras. 
Los álcalis influyen negativamente en un aspecto determinado de la durabilidad que se conoce con el nombre de reacción árido-álcal:s, cuando reaccionan con determinados minerales y compuestos contenidos en las rocas $c_{i} u$ ? constituyen los $11:$ mados áridos susceptibles o reactivos.

Me consta que el problema es perfectamente conocido en este país y, por lo tanto, no voy a detenerme ni mucho ni poco en él, pues el hacerlo sería como ir a dar lecciones a casa del maestro.

Sólo se indica que para paliar la reacción expansiva cuando hay que ut:lizar áridos un tanto reactivos, se deben emplear los cementos — portland- de bajo contenido de álcalis, a los que las normas suelen limitar el contenido de ambos $-\mathrm{Na}_{2} \mathrm{O}$ equivalente- al 0,6 por ciento. Esto no tiene tanto valor ni tanta eficacia como pueda parecer a primera vista, pues los álcalis activos y operantes son todos los presentes en el hormigón, vengan de donde vinieren, y no sólo los aportados por el cemento, que no siempre son los más abundantes.

\section{El yeso del cemento portland}

$\mathrm{Al}$ tratar del $\mathrm{AC}_{3}$ del clínker se ha indicado que su rápida velocidad de hidratación obli. ga a añadir al clínker una o varias formas de sulfato cálcico, las cuales actúan como reguladores del fraguado, retardándolo.

Cada clínker, según su composición y según la finura que se le quiera dar al cemento resultante, requiere un óptimo de yeso para que este cemento presente las mejores características en cuanto a resistencias, estabilidad y durabilidad. El óptimo es tanto mayor cuanto mayor es el contenido de $\mathrm{AC}_{3}$ y de álcalis del clínker, y cuanto mayor haya de ser la finura del cemento.

Sucede con cierta frecuencia que durante la molienda del clínker con el yeso se eleva la temperatura en los molinos de cemento, de modo que el yeso crudo añadido se deshidrata en parte y se convierte en yeso cocido o yeso hemihidrato.

Cuando esto ocurre y el cemento se amasa, se observa un entumecimiento y rigidización pasajera de la pasta, que desaparece al seguir amasando. Este hecho se conoce con el nombre de falso fraguado, y nada tiene que ver con el fraguado rápido del cemento por falta o insuficiencia del yeso, sino que es debido al propio fraguado del yeso coc:do que se ha formado en el molino, a partir del yeso crudo.

El falso fraguado no influye, en general, en las resistencias a cualquier plazo, ni en las demás características del cemento o del hormigón: tan. sólo exige un amasado un poco más prolongado o enérgico para romper la momentánea rigidez adquirida por la pasta.

Pero cuando el falso fraguado se produce en una masa de hormigón, la tendencia del que lo elabora es a deshacer los efectos añadiendo más agua a la masa para aumentar su fluidez. Y como quiera que ésta se recupera después prácticamente en su totalidad, sin más que batir más la masa y sin necesidad de añadir más agua, resulta al final un hormigón mucho más fluido, pero en todo caso con una relación agua/cemento bastante más elevada que la prevista ; es decir, un hormigón de peor calidad: menos resistente, más heterogéneo, menos compacto y, por lo tanto, más poroso y permeable, y menos duradero.

El falso fraguado y sus efectos son particularmente perniciosos cuando se trata de hormi- 
gón preparado en central hormigonera y transportado a distancia en camiones-cuba, en especial en estaciones y climas calurosos donde la desecación es más intensa y rápida También entonces es mayor el peligro de abuso de añadir agua en exceso al hormigón.

Las normas establecen máximos permisibles de adición de yeso al clínker —o de contenidos de yeso en los cementos-, expresados en trióxido de azufre $\left(\mathrm{SO}_{33}\right)$; estos máximos son variables con el tipo, clase y categoría resistente de los cementos, y en los últimos tiempos tienden a subir en no pocos países.

\section{La finura del cemento}

La disolución de un sólido en un líquido es tanto más rápida y tanto más completa cuanto más fino es el sólido. Lo mismo sucede con la hidratación del cemento. De tal manera que cuanto mayor es la finura, mayores son las resistencias alcanzadas por el hormigón a cualquier edad, mayor es la velocidad de desprendimiento del calor de hidratación y mayor, por lo tanto, la temperatura que puede llegar a alcanzar el hormigón. También es mayor la retracción, tanto térmica como hidráulica, y con ella el peligro de fisuración, de agrietamiento y de subsiguiente corrosión de armaduras en el caso de los hormigones armados y pretensados.

Por este motivo se limita a veces la superficie específica de los cementos en las normas, pues todo aumento de resistencia mecánica logrado a base de finura - y no a base de silicato tricálcico- lleva consigo una gran retracción, máxime si las dosificaciones de cemento en el hormigón son elevadas, como sucede en la prefabricación de pretensados.

Cuanto más fino es un cemento, más delicada es la regulación de su fraguado, más yeso se requiere para ello, y mayor peligro existe de que resulte con falso fraguado.

Las anomalías de finura de los cementos dan a veces lugar a dificultades en el fraguado, las cuales repercuten en el amasado, en el transporte, en el vertido, en la puesta en obra y en la compactación del hormigón. Si por un defecto o dificultad técnica de fabricación del cemento - y concretamente en la sección de molienda de clínker en las fábricasel cemento resultante tiene una curva granulométrica distinta de lo usual, con excesiva abundancia o escasez de elementos finos respecto de gruesos, puede haber una parte de conglomerante que fragüe antes que la otra e impida el fraguado normal de esta última. Esto, que es distinto del fraguado rápido o del falso fraguado, produce los mismos o parecidos efectos en el hormigón fresco, e iguales o peores en cuanto al hormigón endurecido.

La excesiva finura o las anomalías granulométricas del cemento dan lugar, sobre todo en hormigones de relación agua/cemento más bien alta, a efectos de segregación por exudación o rezumado (sangrado), los cuales provocan la formación en la superficie del hormigón fresco de una capa más fluida, rica en elementos finos. Al fraguar y endurecer, esta capa se convierte en una corteza distinta del resto de la masa, mal adherida a ésta, y con una retracción mucho mayor. Esto hace que la corteza se fisure, agriete y descascarille, perjudicando el aspecto superficial del hormigón. Puede dar lugar, incluso, a una fuerte retracción plástica o de acomodación conducente al agrietamiento del material, sobre todo si concurre una desecación rápida e intensa del mismo. Pero de esto se tratará después con mayor detalle.

Como resumen de cuanto queda dicho, y de una forma gráfica, el esquema 16 pone de relieve las relaciones cualitativas y semicuantitativas existentes entre las características 
tecnológicas más destacadas de los hormigones y de los cementos, y la composición y constitución, es decir, la naturaleza química, de estos últimos.

\section{Composición potencial}

Cabe preguntarse: ¿y cómo precisar si un cemento portland dado es rico o pobre en uno $\mathrm{u}$ otro silicato, o en uno u otro aluminato, para poder determinar, en función de lo expuesto, qué utilización le va mejor y en qué condiciones no debe emplearse?

Esto lo resuelve el cálculo de la llamada composición potencial del cemento (el "cálculo potencial"), hecho a base de los datos de su composición química porcentual, de acuerdo con las ecuaciones de los esquemas 17 y 18 .

En ellas se debe entender por cal, $\mathrm{CaO}$, la aal combinada, es decir la diferencia entre la cal total y la cal libre. Cuando no exista dato de ésta última, por no haber sido determinada analíticamente, se puede tomar como cal combinada la cal total. Esto implica un cierto error, pero los resultados del cálculo siguen teniendo suficiente valor indicativo.

La primera ecuación contiene la correspondiente corrección por el yeso contenido en el cemento, ya que el cálculo potencial es sólo aplicable al clínker de cemento portland normal $\mathrm{u}$ ordinario.

Esto es importantísimo porque el cálculo no sirve, por principio, para cualesquiera otros cementos. El aplicárselo conduce a resultados absolutamente erróneos, cuando no también absurdos y desconcertantes.

\subsection{Cementos con escorias siderúrgicas}

Las escorias siderúrgicas deben cumplir, naturalmente, unas determinadas condiciones para su empleo en la fabricación de estos cementos.

Las escorias básicas granuladas de horno alto - que son las idóneas- abundan más en componentes silicoaluminosos que en cal, y poseen propiedades hidráulicas latentes; es decir, amasadas con agua fraguan y endurecen de por sí, y mezcladas con clínker y amasadas dan lugar, además, a compuestos hidráulicos con la cal liberada en la hidratación del clínker. Esto último es el resultado de un cierto "efecto puzolánico".

Los diversos cementos siderúrgicos se diferencian únicamente en aquellas características que dependen de las distintas proporciones de clínker y escoria en unos y otros, las cuales suelen oscilar entre valores de clínker comprendidos entre 20 y 70 por ciento, y valores de escoria comprendidos entre 80 y 30 por ciento (en general, no menos de 60 por ciento). Naturalmente que los cementos siderúrgicos se distinguen también por su categoría o calidad resistente.

Las escorias dan lugar a procesos de hidratación más diferidos por lo que, en general, los cementos siderúrgicos son de endurecimiento más lento que los portland de igual categoría resistente.

Los cementos siderúrgicos en general desprenden un calor de hidratación menor que los portland, y al mismo tiempo liberan una cantidad de cal también menor, en la proporción en que la escoria sustituye al clínker. La reserva alcalina de las pastas de los cemen- 
tos siderúrgicos es, por lo tanto, más baja que la de las pastas de portland.

Las escorias y, en consecuencia, los cementos siderúrgicos, pueden contener una cierta proporción de sulfuros, a diferencia de los cementos portland.

La menor reserva alcalina y la presencia de sulfuros hacen que los cementos siderúrgicos no protejan a las armaduras contra la corrosión en la medida en que lo hacen los portland; por el contrario, los sulfuros pueden dar lugar a un determinado tipo de corrosión, por lo cual no son recomendables para hormigón pretensado.

En contrapartida, la menor cantidad de cal liberada en la hidratación y la naturaleza de los productos creados por ella hacen que estos cementos sean mucho más durables que los portland frente a cualquier tipo de agresividad de naturaleza química, y en especial frente al ataque ejercido por aguas de mar, yesos y sulfatos en general. Se emplean por ello en hormigones de escolleras y de cimentaciones.

Desde el punto de vista de la estabilidad, lapresencia de sulfuros, su posible oxidación a sulfatos y la acción posterior de éstos, podrían ser motivos de expansión.

\subsection{Cementos puzolánicos}

Los cementos puzolánicos están constituidos por clínker y una puzolana natural o artificial, en proporciones variables no estipuladas en general, pero que suelen oscilar entre 25 y 40 por ciento.

Por puzolanas naturales se entienden los materiales rocosos de origen volcánico capaces de fijar cal a la temperatura ambiente y de formar compuestos con propiedades hidráulicas. Por puzolanas artificiales se entienden las cenizas volantes, las arcillas activadas y los productos que, como los citados, tienen propiedades análogas a las de las puzolanas naturales.

Las normas suelen imponer algún método de ensayo para determinar, bien sea la actividad de la puzolana, o bien la puzolanicidad del cemento puzolánico. De entre los últimos, uno de los más aceptados es el de FRATINI, de cuyo fundamento da idea el gráfico del esquema 19: un cemento es puzolánico cuando su punto representativo, según el resultado del ensayo, se sitúa por encima de la curva; y no lo es cuando se sitúa sobre ella o por debajo.

A.demás de esta interpretación de los resultados del ensayo de FRATINI llevado a cabo en las condiciones experimentales que en él se estipulan, existen unos criterios empíricos para la valoración más cuantitativa de dichos resultados.

Los cementos puzolánicos, por el hecho de tener sustituida una parte del clínker por la cantidad equivalente de puzolana, liberan menos cal que los portland en la hidratación. Pero, además, una buena parte de esa cal se combina por acción puzolánica para dar nuevos compuestos hidráulicos. Así, pues, aunque la basicidad de las pastas de los cementos puzolánicos sea prácticamente la misma que la de los cementos portland ( $\mathrm{pH} 12-12,5)$, su reserva alcalina es menor.

Este hecho puede tener importancia en dos aspectos relacionados con la durabilidad. Uno es el de la resistencia notablemente mayor de los hormigones de cementos puzolánicos frente a los ataques químicos producidos por aguas puras, ácidas, carbónicas agresivas e 
incluso selenitosas y marinas, lo cual los hace aptos para su empleo en obras marítimas, cimentaciones y obras sumergidas. Otro aspecto es el de la protección, ligeramente menor, sobre todo a largo plazo o en ambientes de cierta agresividad, que los cementos puzolánicos pueden conferir a los hormigones, en el caso de los armados y pretensados.

Desde el punto de vista mecánico-resistente, los cementos puzolánicos son conglomerantes de endurecimiento más lento que el de los portland, pero que a largo plazo pueden dar reșistencias iguales o superiores a las de los portland de categoría equivalente. Son, por ello mismo, cementos de relativamente bajo calor de hidratación, lentamente desprendido, especialmente adecuados para hormigonar en grandes masas, como es el caso de las presas.

En cuanto a estabilidad, las pastas de los cementos puzolánicos pueden ser ligeramente más retractivas que las de los portland equivalentes, en razón de la mayor finura a que se suelen moler, y de la cantidad de agua algo mayor que suelen exigir a veces para lograr pastas, morteros $\mathrm{u}$ hormigones de una consistencia dada.

Como los cementos siderúrgicos, y aún más que éstos, los cementos puzolánicos, a causa del "efecto silícico" a alta temperatura mencionado después al tratar del ensayo del autoclave, son especialmente indicados para tratamientos térmicos del hormigón en prefabricación, que tanta importancia tienen en la cada vez más pujante construcción industrializada.

Lo expuesto hasta el momento ha pretendido poner de relieve las evidentes relaciones existentes entre las características de los cementos y las propiedades y el comportamiento del hormigón, en los aspectos más destacados del mismo: su resistencia mecánica, su estabilidad y su durabilidad.

Pero todo ello no quedaría tal vez suficientemente claro, si no se ilustrara con ejemplos reales de gran relieve en obra, en los cuales suelen estar involucrados serios problemas de opción, de decisión y de responsabilidad, con importantes implicaciones tanto técnicas como económicas. Estos ejemplos se van a centrar, en lo que sigue, en aspectos diversos de la expansión, de la retracción y fisuración, y del entumecimiento del hormigón, problemas que afectan según los casos a las presas, a las cimentaciones, a las grandes losas de pavimentación y a los forjados, a las obras portuarias y marítimas en general, $\mathrm{v}$ a la prefabricación de elementos de hormigón.

\section{LA EXPANSION}

Una de las causas de inestabilidad del hormigón es la expansión. Los agentes y las acciones que la producen pueden ser muy variados: unos inherentes al hormigón; otros no.

Entre los primeros se cuentan algunos correspondientes al cemento ; por ejemplo, la hidratación tardía de la cal libre y/o de la magnesia libre (periclasa) del clínker, o la formación tardía de ettringita por sobredosificación de yeso en el cemento, como ya se ha expuesto anteriormente.

Otros son relativos a los áridos en exclusiva; por ejemplo, la oxidación de algunos sulfuros metálicos como las piritas, la pirrotita o la marcasita, contenidos en determinados áridos insanos.

$Y \cdot o t r o s$ son concernientes a la interacción entre áridos y cemento; por ejemplo, la reac- 
ción árido-álcalis en alguna de sus modalidades (álcali-sílice, álcali-silicatos o álcali-carbonatos), ya mencionada.

Entre las acciones y agentes no inherentes al hormigón están, por ejemplo, los ataques al mismo por sulfatos externos - agua de mar o yeso del terreno-, con formación de ettringita (y/o thaumasita, si media además un proceso de carbonatación).

Hay una tercera modalidad de acciones y agentes que producen un tipo de expansión sui géneris, particularmente dañina: la oxidación y la corrosión de las armaduras del horm1gón armado o pretensado, motivada por diversas causas y mecanismos, tanto intrínsecos como extrínsecos del hormigón.

De todos ellos existen típicos ejemplos, clásicos y reales, de cuya consideración se pueden sacar las debidas conclusiones en cuanto a! empleo de los materiales más idóneos y, en particular de los cementos, para evitar males.

\subsection{La expansión por cal libre}

Por lo que respecta al contenido de cal libre de los cementos, del que ya se ha hablado, considérese el caso de una presa en cuya masa de hormigón se temen expansiones por sospecha -o por certeza- de un cierto contenido de cal libre en el cemento empleado. Pueden presentarse dos situaciones extremas, en función del desarrollo de la resistencia y de la evolución de la expansión: o la resistencia crece más deprisa que los empujes de la expansión y en todo momento va muy por delante de ellos, en cuyo caso no hay nada que temer, o los esfuerzos de la expansión llegan a alcanzar e incluso a rebasar en algún momento los valores de la resistencia, en cuyo caso, ya antes, se puede producir la ruptura del hormigón (esquemas 20 y 21).

Para evitar esta última situación habrá que procurar: a) que el cemento no contenga cal libre por encima de un cierto límite - en general que no contenga componentes expansivos, pues el razonamiento es igualmente válido para la magnesia libre (periclasa)-; y/o b), que el hormigón (por su diseño, y en particular por su dosificación de cemento, por el tipo de éste, etc.), desarrolle su resistencia con ritmo suficiente para afianzarse frente a ligeros esfuerzos de expansión. Porque, lo que está claro es que si una fuerza "externa" - peso propio- y otra intrínseca del material —resistencia del hormigón-, son en conjunto y en cada punto muy superiores a una fuerza "interna" — presión de expansión - también en conjunto y en cada punto, los efectos de ésta última fuerza no tienen lugar y no se manifiestan; es decir, no hay expansión ni rotura del material.

Estas consideraciones han llevado en dos casos que el que les habla conoce, a dos soluc:ones opuestas. En uno de ellos, a demoler bastantes miles de metros cúbicos de hormigón ya puestos en obra; en el otro, a conservar la obra que, al cabo de unos seis o siete años de tal toma de decisión, se mantiene en perfectas condiciones.

En el primero de los casos se trataba de una presa en construcción en determinada región de determinado país. Al cabo de un cierto período de hormigonado, se analizó el cemento portland que se venía utilizando y se apreció en él un contenido de cal libre que hizo pensar en su posible carácter expansivo. No se habían conservado muestras de las partidas de cemento empleadas con anterioridad, ni se tenían datos analíticos de ellas, de modo que no se pudo saber si adolecían o no del mismo contenido de cal libre y del mismo peligro potencial de expansión. La alternativa era, pues, o bien demoler la parte sospechosa de 
la obra; o bien conservarla con todos los riesgos. Se optó por lo primero, viéndose afectadios por la demolición varios miles de metros cúbicos de hormigón.

nivi::

En el segundo caso se trataba de otra presa en construcción, en otro país distinto. Se daba la circunstancia de tener la certeza de un contenido alto de cal libre en el cemento empleado - que, por cierto, era de horno vertical-, así como de ser fuertemente expansivo en el autoclave, pese a lo cual, y por consideraciones análogas a las expuestas en lo que precede, así como por la zona de obra a la que el hecho podía afectar, se decidió mantener la parte de obra ya hormigonada y proseguir, sin que hasta el momento, y al cabo del tiempo dicho, haya habido novedad. Tal vez esta solución hubiese sido también la mejor en el primer caso.

Estas considerac:ones, junto con otras relativas, no ya a expansiones, sino por el contrario a retracciones plásticas, térmicas e hidráulicas de los hormigones masivos de las gran. des presas, han conducido a recomendar para estos hormigones el empleo de cementos puzolánicos, de buenas resistencias a medio y largo plazo y de bajo calor de hidratación, así como susceptibles de dar hormigones más impermeables.

Y han conducido también a la convicción de que es potencial y realmente mucho más económico invertir lo que haga falta en el riguroso control de los materiales, y en particu. lar del cemento, que pasar por alto este detalle, sobre todo en obras de gran envergadura en las que los gastos de control se diluyen mucho más en el costo total de la obra.

Pero en esto del control, de los métodos de ensayo para ejercerlo, de la interpretación y valoración de los resultados de los mismos, y hasta de su grado de fiabilidad, hay mucho que decir, precisamente en cuanto se refiere a los métodos para determinar la expansión "potencial" - que no real en la práctica - de los cementos. Buscar el máximo de seguridad por caminos inadecuados conduce a veces, si no al desastre, que tal no cabe, sí al menos a la confusión.

Un ejemplo: al énsayo de expansión de cementos en autoclave según las Normas ASTM se le ha considerado y considera como el más drástico y, por lo tanto — de aquí el confusionismo y el error-, como el de mayor garantía. Hasta el punto de haberse afirmado que cuando un cemento no da expansión en el autoclave jamás será expansivo en la práctica, y que el hecho de que un cemento dé expansión en el autoclave no implica necesariamente que lo vaya a hacer también en la obra. Esto se llama situarse, en todo caso, del lado de la mayor seguridad.

Pero realmente las cosas no son siempre así. Lo son sólo en el caso de que los cementos ensayados en el autoclave sean cementos portland "puros", es decir, constituidos en exclusiva por mezclas de clínker y yeso, ya que entonces el autoclave pone de manifiesto la expansión producida por casi todas las causas de expansión intrínseca del cemento - no así en lo relativo a la expansión diferida originada por una posible sobredosificación de yeso al clínker-.

Pero no sucede lo mismo cuando se trata de cementos con adiciones - sobre todo activas: puzolanas, cenizas volantes o escorias siderúrgicas, o mezclas de ellas-, es decir, de cementos con constituyentes secundarios. Porque, en tal caso, en vez de tener lugar en el autoclave la hidratación directa de los componertes expansivos - cal libre y/o magnesia libredel cemento, la cual provoca la expansión, lo que tiene lugar en una "síntesis" directa, bajo presión y a alta temperatura, de productos hidratados de reacción entre la cal libre -óxido cálcico- y la cal liberada por hidrólisis — hidróxido cálcico- del cemento, por 
una parte, y los constituyentes ácidos sílico-aluminosos del material de adición -en virtud del llamado "efecto silícico"-. Este tipo de proceso, que elimina la hidratación directa y previa de la cal libre, no tiene, a diferencia de dicha hidratación, carácter expansivo. Es, por otra parte, un proceso tan conocido. que se utiliza industrialmente en la fabricación de ladrillos y productos silicocalcáreos.

Pero da la casualidad de que el hormigón de las obras no se hace para someterlo a las condiciones del autoclave - 21 atmósferas de presión de vapor a la temperatura de $215^{\circ} \mathrm{C}$ durante varias horas-, por lo cual en dicho hormigón no se produce la "síntesis" directa. no expansiva antes citada, sino la hidratación previa, sí expansiva, de la cal y/o de la magnesia libres del cemento. Y esto es lo que puede ocurrir y ocurre en la práctica real a plazo más largo —en el caso de la magnesia—, o más corto —en el caso de la cal一, al margen y con independencia del resultado engañoso del ensayo del autoclave.

Consecuencia: los cementos con constituyentes secundarios -adiciones más o menos activas (e incluso aparentemente inertes) -, como los puzolánicos o los de escorias, no dan expansión en el autoclave, pero a pesar de ello pueden ser expansivos en la obra. Lo que quiere decir que, en tal caso, los resultados del ensayo del autoclave sitúan al técnico del lado de la "inseguridad", muy al contrario de lo pretendido y de lo proclamado.

Que esto es así se ha comprobado experimentalmente -el que les habla lo ha hecho-, añadiendo a cementos con 4 y 6 por ciento de cal libre, fuertemente expansivos en la práctica y también en el autoclave - hasta destrucción en este último caso-, cantidades crecientes entre 1 y 10 por ciento de puzolanas naturales, cenizas volantes y escorias siderúrgicas. Al crecer la cantidad adicionada disminuye la expansión hasta anularse para un porcentaje intermedio, convirtiéndose incluso en retracción para porcentajes de adición superiores.

Por esta razón las Normas ASTM limitan ya, no sólo la expansión en autoclave, sino también la retracción cuando se trata precisamente de cementos puzolánicos o similares. Pero esto tampoco tiene un sentido claro, pues a efectos retractivos el hormigón real no va a estar nunca sometido a las condiciones del autoclave, ni los mecanismos y reacciones causantes de retracción son iguales en el ensayo que en la práctica (esquema 22).

Por eso también las actuales normas españolas para cementos aplican el ensayo del autoclave para determinar la expansión "potencial" de los cementos portland "puros" solamente, mientras que adoptan el ensayo de las agujas LE CHATELIER para medir la expansión de todos los demás cementos, como sucede, en general, en la mayoría de los demás países (esquema 23).

\subsection{La expansión por yeso}

Se refiere ésta -en este caso- a la que se produce con retardo en un hormigón por haber utilizado en él un cemento con exceso grande de yeso añadido como retardador y regulador del fraguado del clínker.

El exceso de yeso en el cemento es excepcional y, por lo tanto muy poco frecuente. Primero, porque las normas de todos los países limitan su contenido - generalmente en función del tipo de cemento y de su contenido en aluminato tricálcico si se trata de un portland-; y, segundo, porque los fabricantes lo tienen muy en cuenta. De lo primero son un ejemplo clásico, entre otras, las Normas ASTM. 
Sin embargo, esto no impide que en alguna ocasión aislada, generalmente por una avería o un descontrol en los dosificadores de yeso de los molinos de clínker y por una cierta demora en la advertencia de ello, salga de fábrica alguna partida de cemento sobredosif:cada de yeso:

Cuando esto sucede y el cemento se emplea, el hormigón resultante se puede agrietar y romper por expansión "desde dentro", ya que en su interior se forma ettringita - "sal de CANDLOT", compuesto altamente expansivo llamado antaño "bacilo de cemento"-, por reacción entre el yeso y el aluminato tricálcico del clínker (esquema 21).

El que les habla conoce un caso de excepc:ón en que ocurrió esto, habiéndose llegado a hormigonar con un cemento "pasado de yeso" las estructuras de varios bloques de viviendas, los cuales hubieron de ser demolidos, con los consiguientes quebrantos económicos.

La moraleja de ello puede ser la necesidad, más que conveniencia, del autocontrol riguroso de la producción de cemento en fábrica y del control de recepción del mismo en obra - en central hormigonera, lo cual es más fácil-.

\subsection{El ataque por sulfatos}

Otras veces los procesos expansivos y destructivos del hormigón, si bien se generan en el interior de éste - como los debidos a exceso de yeso en el cemento- y actúan desde dentro hacia afuera, tienen un origen exterior y anterior: la penetración desde el medio ambiente de agentes agresivos, entre los que se encuentran, como más típicos y frecuentes, los sulfatos - cálcico y/o magnésico-, bien sea de los terrenos en los que se hacen obras de cimentación o asientos de losas de hormigón, o bien del agua de mar, en contacto con la cual las estructuras de hormigón hayan de estar en contacto.

Habida cuenta de que la primera etapa - y condición indispensable - para este tipo de ataque es la penetración del agresivo en el hormigón, el mejor remedio debe consistir en evitar al máximo y por todos los medios posibles dicha penetración.

Para ello, la primera y - con mucho- la principal medida lógica, consiste en hacer hormigones poco "penetrables" - permeables, porosos...-en los que sea muy difícil la entrada del agresivo. Y para esto, a su vez, es preciso que el hormigón sea lo más compacto posible, lo cual depende de su diseño, de sus materiales, de las proporciones de éstos, de los métodos de transporte, puesta en obra, compactación y consolidación, y de la adecuación de su curado. En definitiva, de la bien conocida aunque no siempre bien practicada tecnología del hormigón.

De esta tecnología, y por lo que concierne exclusivamente al hormigón como material, hay. que destacar que la calidad de éste se rige por los dos consabidos parámetros, por otra parte importantísimos, determinantes en muy gran medida de su comportamiento: uno es la relación árido/cemento, la cual tiene su expresión numérica y práctica en la "dosificación de cemento", es decir, en los kilogramos de cemento por metro cúbico de hormigón; el otro es la relación agua/cemento (o su inversa llamada concentración: relación cemento/ /agua). Es evidente y de general conocimiento que en condiciones ordinarias y dentro de ciertos límites un hormigón es tanto mejor cuanto menores sean ambas relac:ones, es decir, cuanto más cemento y menos agua tenga, a igualdad de todo lo demás. Esto es particularmente válido por lo que se refiere a la compacidad, a la impermeabilidad y a la impenetrabilidad del material. 
Por tal motivo, el ahorro de cemento que pueda suponer el empleo de un cemento de gran resistencia frente a otro de resistencia menor, en un mismo hormigón, es una mala práctica, totalmente recusable, pues, aun cuando se mantenga la misma resistencia, se puede perjudicar muy considerablemente la compacidad y la impermeabilidad del hormigón, lo cual, en determinados casos, - como los de las presas, los diques y las obras marítimaspuede ser desastroso, porque, al final y a corto plazo, acaba arruinándose también la resistencia. Recuérdese de paso y al respecto lo indicado al principio: la resistencia mecánica del hormigón no es la única y, en ocasiones, ni siquiera la más importante de las características del hormigón, entre otras cosas porque casi siempre suele ser la suficiente, y porque depende de otras características que la afectan mucho y que, por ello, en muchos casos deben pasar al primer plano.

La segunda medida para evitar el ataque al hormigón, y que no excluye a la primera, sino que la complementa con eficacia, consiste en proteger exteriormente al hormigón masivo -y, en su caso, también al armado y al pretensado- mediante tratamientos y/o recubrimientos que lo aislen del contacto - $\mathrm{y}$, por lo tanto, de la penetración- del agente o medio atacante. Esto se puede lograr por acciones directas sobre el propio hormigón, o. más indirectamente, por "apantallamiento" mediante barreras u obstáculos que impidan o dificulten el acceso del agresivo a la superficie del hormigón. Se podrían exponer ejemplos de unas $u$ otras medidas preventivas, pero no se estima necesario.

La tercera medida (que tampoco excluye a las anteriores cuando todas son necesarias - ¿y suficientes?-, pero sobre todo a la primera, de la cual es un magnífico complemento) consiste en utilizar materiales sanos, estables y durables dentro del propio hormigón, y frente a los agentes del exterior que pueden penetrar en el material y poner en peligro su estabilidad y su durabilidad. En el caso presente se hace referencia específica a los cementos.

Los cementos resistentes en distinta medida a los ataques por sulfatos pueden ser de varios tipos y clases. Dentro de los portland, y por lo ya señalado, lo son los de bajo contenido de aluminato tricálcico y de ferrito-aluminato tetracálcico, por las razones ya indicadas anteriormente, y en particular si además son pobres en silicato tricálcico. Este es un motivo -o si se prefiere una consecuencia- de que en todas las normas en general (y en particular en las ASTM) los cementos de moderada o alta resistencia a los sulfatos coincidan con los de moderado o bajo calor de hidratación, respectivamente, dentro de los cementos de tipo portland (esquema 25).

Pero los cementos más genuinamente resistentes al ataque por sulfatos en general no son precisamente los de tipo portland, sino los que contienen escorias o los puzolánicos. El orden de preferencia de unos u otros depende de la especificidad del sulfato y de la naturaleza del medio agresivo, en cada caso. Por ejemplo: a los ataques por agua de mar resisten bien los cementos siderúrgicos, siempre que su contenido de escoria no sea inferior a uno dado, que, según diferentes criterios, puede oscilar entre 60 y 80 por ciento -media centrada entre 65 y 75 por ciento-. Y, por supuesto, siempre que la escoria sea de horno alto, granulada por temple con aire y/o con agua - es decir, que se trate de una escoria predominantemente vítrea-, y con carácter básico garantizado por el cumplimiento de alguno de determinados índices químicos.

Frente a ataques por yesos y también por agua de mar pueden ser asimismo eficaces los cementos puzolánicos. Buena prueba de ello son las obras portuarias de los romanos, en las que se emplearon conglomerantes puzolánicos, si bien distintos a los actuales cementos puzolánicos. Pero, en todo caso, cualesquiera de estos cementos tienen motivos para resistir mejor que los portland los ataques por sulfatos y agua de mar. 
Lo que sucede, es que, a veces, el ingeniero civil tiene una cierta prevención contra el empleo de cementos distintos del portland "puro" (clínker y yeso en exclusiva), unas veces por inercia y otras por temor - no siempre infundado- a fraudes.

Los cementos siderúrgicos y puzolánicos "serios" y de garantía son de fiar, sobre todo si se utilizan adecuada y racionalmente - esto es importante-. La garantía en los primeros viene dada por las condiciones mineralógicas y químicas de las escorias empleadas, tal como queda indicado (esquemas 26 y 27). La garantía de los segundos la suele dar algún ensayo, bien de la puzolana o, lo que es mucho más lógico y racional, del propio cemento puzolánico, mediante algún criterio de puzolanicidad, entre los que destaca el de FRATINI. Es un ensayo de "sí o no", esto es, de "todo o nada", sin carácter cuantitativo, pero al que, según la acreditada escuela italiana se le puede dar un tal carácter de una forma empírica basada en la propia experiencia italiana (esquema 28).

Dentro del ataque por sulfatos, en cuya mecánica química detallada no se va a entrar. destaca por su especificidad el causado por e! sulfato magnésico. En este caso a la acción agresiva del anión — sulfato- se suma la del catión —-magnesio-, el cual puede intercambiarse parcialmente con el calcio de la portlandita y de la tobermorita de la pasta hidratada del cemento para formar en ambos casos brucita insoluble - con carácter potencialmente expansivo-, y para transformar en el segundo caso un silicato cálcico hidratado, hidráulico y resistente, en un silicato cálcico-magnésico hidratado, que no es ni lo uno ni lo otro, con lo cual la resistencia de la pasta de cemento sale perdiendo mucho. Pero la brucita puede también contribuir con su formación al llenado y obstrucción de los poros y canales capilares de la pasta hidratada, obstaculizando o retardando la nueva entrada y la mayor penetración del agresivo en el hormigón. En tal sentido puede ejercer un papel protector.

Por todo ello resulta tan difícil determinar qué cemento resiste mejor un ataque por sulfato magnésico o por agua de mar, pues a los factores químicos se unen siempre, indisolublemente, factores físicos relativos a la estructura interna de la pasta de cemento. En principio, los cementos más resistentes al sulfato magnésico serán aquéllos que simultáneamente resistan al anión sulfato y al catión magnesio.

Dentro de los cementos portland, por lo primero lo serán los de bajo contenido de aluminatos y ferritos cálcicos; y, por lo segundo, los de bajo contenido de silicato tricálcico - y, consecuentemente, de alto contenido de silicato bicálcico-. Pero, no por casualidad, tales cementos son, entre todos los portland, los de menores resistencias mecánicas a corto, medio y largo plazo. Esto prueba que lo bueno de los cementos en unos aspectos puede ser y es malo en otros, lo cual hace a veces dudosa la elección.

Cualquiera de los cementos de otros tipos distintos del portland -siderúrgicos, puzolánicos- resistirán mejor que los portland la acción del sulfato magnésico. En primer lugar por la acción diluyente de la escoria o de la puzolana respecto de los aluminatos y ferritos cálcicos del clínker, lo cual, por una parte, dulcifica el ataque del anión sulfato; y, por otra parte, atenúa la formación de brucita y la degeneración de la tobermorita. En el caso de los cementos puzolánicos esto último tiene menor efecto que en el caso de los cementos siderúrgicos, dependiendo también y mucho de la naturaleza de la puzolana.

Asi, pues, el orden preferente de resistencia a los sulfatos en general, y/o al sulfaio magnésico en particular sería, a igualdad o semejanza de otros factores, el siguiente: cementos siderúrgicos, y cementos portland específicamente resistentes a sulfatos, o cementos puzolánicos. Y el ideal de los ideales sería: cementos siderúrgicos o puzolánicos hechos con clínker propio de cementos portland específicamente resistentes a sulfatos —esto es, 
de bajo contenido de aluminatos y ferritos; y aún de silicato tricálcico, si la resistencia mecánica de los mismos lo permite en los usos para los que son empleados-.

Una destrucción del hormigón, aunque mucho menos frecuente, causada por sulfatos alcalinos -en general por compuestos alcalinos' solubles-, es la llevada a cabo por la reacción árido-álcalis en hormigones que contienen áridos susceptibles de tal reacción. En este caso - como en el del sulfato magnésico- el ataque no sólo es producido por el anión - sulfato-, sino también por los cationes.

Los sulfatos alcalinos pueden provenir en algún caso del exterior y penetrar en el hormigón, o pueden estar contenidos en el cemento. Hoy lo están en mayor proporción que en otros tiempos, dados los actuales sistemas y maquinaria para fabricar cemento con mejor rendimiento térmico, buscando y consiguiendo el ahorro de combustibles y energía. De aquí la razón de que en el caso de hormigones con áridos reactivos cuyo empleo sea inevitable -la primera y mejor medida sería evitarlo-, se deban emplear cementos de bajo contenido de álcalis, para cuyo total, expresado en forma de óxido sódico equivalente, las normas suelen fijar un límite superior tolerable de 0,6 por ciento, como ya se indicó anteriormente.

Cuando los sulfatos alcalinos provienen del exterior, a la reacción árido-álcalis se suma el ataque del anión sulfato, por lo cual los cementos portland utilizables, además de ser de bajo contenido de álcalis, deberán reunir las condiciones de los específicamente resistentes a sulfatos.

\subsection{El entumecimiento}

Otro motivo de inestabilidad, sobre todo en las presas, - un ejemplo de lo cual ha podido ser observado hace unos años en un determinado país-, es el de las presiones y empujes de naturaleza hidráulica ( $\mathrm{y}$ por lo tanto física) que a veces se producen en grandes masas de hormigón, y que son debidos a entumecimiento, imbibición o "hinchamiento por capilaridad" - absorción capilar de agua - por parte del hormigón.

El ejemplo al que se alude se refiere a un bloque de unos 70 metros lineales (unos 3.500 metros cúbicos) de hormigón, en un lateral del coronamiento de una presa de gravedad. Los bloques inferiores y adyacentes análogos habían sido hasta el momento de unos 14 metros lineales (unos 700 metros cúbicos), es decir, de una masa y volumen cinco veces menores (esquema 29).

El bloque de referencia era de un hormigón distinto al de los otros bloques: de mejor calidad y con mayor dosificación de cemento, precisamente por corresponder a la zona de compuertas. Por ello - y por otras razones que se indicarán después- podía haber habido, y de hecho hubo, acciones y efectos diferenciales.

Aparte de esto, y por motivos técnicos, la presa una vez construida, hubo de estar durante varios años en seco, sin embalsar agua. Las alternancias estacionales $\mathrm{y}$, por lo tanto, climáticas en cuanto a temperatura y humedad relativa de la atmósfera, fueron varias y transcurrieron entre límites muy amplios, y con carácter también diferencial por lo que se ref:ere a los paramentos de aguas arriba y de aguas abajo de la presa.

Al proceder después al embalsado de agua hasta el nivel máximo, se empezó a apreciar un cierto "desplazamiento" ligero y lento, pero continuo a lo largo del tiempo, del bloque de referencia. 
La explicación provisional es la siguiente: por razones de orientación, insolación y acción de los vientos predominantes, todo ello considerado en conjunto y en cuanto a su resultante final, el paramento de aguas abajo pudo desecarse mucho más rápida, intensa y profundamente que el paramento de aguas arriba. Como consecuencia, la humedad de la masa de hormigón intermedia o más próxima al paramento de aguas abajo pudo emigrar poco a poco y por difusión hacia éste, mientras que el paramento de aguas arriba se pudo desecar a otro ritmo distinto - más lento y menos intenso-. Pudo haber quedado así una zona intermedia de hormigón aún húmedo, más desplazada hacia el paramento de aguas arriba (esquema 30 ).

Al proceder al embalsado se pudo embeber mucho más intensa y rápidamente todo el hormigón del paramento de aguas arriba, y precisamente más el de la parte inferior del mismo, ya que en dicha zona la penetración de agua por imbibición se vería favorecida por la presión hidrostática.

En cuanto a la parte superior del paramento, la imbibición pudo ser también más fuerte en el bloque de referencia que en los bloques adyacentes, ya que por su mayor dosificación de cemento el primero contendría lógicamente, por unidad de masa o de volumen, una mayor cantidad de geles capaces de encogerse por desecación y por desorción en la etapa seca, y de hincharse y entumecerse por el agua absorbida y adsorbida fisicoquímicamente en la etapa de embalsado.

Esto sin duda pudo dar lugar a unos efectos diferenciales, manifestados como empuje del bloque, desde atrás y abajo hacia adelante y arriba, apoyado en los subyacentes e incluso ayudado por el propio empuje de éstos, y manifestados también como presiones laterales ejercidas sobre los bloques contiguos.

Por otra parte, la penetración rápida y a fondo del agua por el paramento de aguas arriba pudo experimentar una acción de frenado —en cuanto a su difusión hacia adelante-y, por lo tanto, un retardo al alcanzar la zona de hormigón todavía húmedo, antes citada.

En consecuencia, el movimiento del bloque en cuestión pudo ser, más que un "desplazamiento" - o además de un desplazamiento - una especie de giro o de "vuelco", o cuando menos de incurvación alrededor de una hipotética charnela longitudinal, situada precisamente en la parte inferior del bloque, bien al borde de éste coincidente con el paramento de aguas abajo de la presa, o bien a mayor o menor profundidad de la zona de separación entre el hormigón del bloque embebido y entumecido, y el hormigón todavía seco o mucho más seco.

En suma, el efecto parece ser como si el bloque hubiera sido "apalancado" hacia arriba y desde detrás, es decir, desde el paramento de aguas arriba, más que por una palanca mecánica, por una especie de gigantesco gato hidráulico.

Una prueba de la verosimilitud de lo expuesto es la rotura, en dos puntos coincidentes con los extremos laterales del bloque, del barandal de hierro del coronamiento de la presa, y del bordillo de la acera correspondiente, también de hierro, por sendos esfuerzos simétricos -en realidad el mismo y único esfuerzo de cizalla producido por el giro o "apalancamiento" del bloque-.

Ahora la cuestión es saber hasta cuándo y dónde puede continuar el movimiento del bloque y con qué consecuencias. Es de prever que la acción y el efecto puedan continuar hasta que el bloque entero, por sus partes de aguas arriba y de aguas abajo, adquiera el mismo grado de imbibición e hinchamiento o entumecimiento. O, mejor aún, hasta que se alcance un equilibrio en régimen estacionario, por el cual el agua que penetre por el paramento 
de aguas arriba no haga más que mantener la posición final -de equilibrio- alcanzada ya por el bloque [esquema 31 tomado de M. FERNANDEZ CANOVAS "Entumecimiento higrométrico del hormigón": Materiales de Construcción - IETCC. Núm. 177 pág. 27, enero-febrero-marzo (1980), y esquema 31 bis].

Si la supuesta "charnela" se sitúa en el borde inferior del bloque y prácticamente en la superficie del paramento de aguas abajo de la presa, ello se manifestaría en la parte exterior del paramento y tendría que notarse, cosa que hasta ahora no ha ocurrido. Y si se situase en una zona más o menos interna del paramento, no se notaría —como es el caso--, pero haría pensar en un posible debilitamiento - ¿rotura?- longitudinal del hormigón del bloque, por su parte inferior y a la altura de dicha zona. Este es un aspecto que, en todo caso, exige una comprobación y una estrecha vigilancia.

De cualquier modo el hecho de que el bloque sea en masa y volumen cinco veces mayor que los adyacentes y subyacentes; que sea de un hormigón mejor y con una dosificación de cemento más elevada; que, como consecuencia de todo ello, haya podido experimentar en su momento mayores retracciones de todo tipo - de fraguado (irreversible), térmica e hidráulica (reversibles)-, supone una "disimetría" o una "heterogeneidad" con el resto del paramento de la presa, lo cual puede ser origen y asiento de los comportamientos diferenciales señalados como posibles y aún probables, y explicar los efectos observados.

Desde un punto de vista "doctrinal" se podría decir, con carácter absolutamente general, que tales heterogeneidades y disimetrías habíía que evitarlas al máximo en todos los casos, pues como en el de la corrosión de las armaduras en los hormigones armados y pretensados - mencionado de pasada aquí y ahora como más típico-, son potencialmente siempre y realmente en muchos casos, origen de desastres catastróficos.

La moraleja particular del caso es que, aparte de las vicisitudes poco favorables del mismo - fuerte, continuada y profunda desecación previa de hormigón de la presa y, a mayor abundamiento, con carácter diferencial-, en situaciones análogas no deben emplearse hormigones de muy alta dosificación ni hechos con cementos de muy alta resistencia y elevado calor de hidratación - ya se deban ambos a composición química y/o a finura de molido excesiva-, por los peligros de fuertes retracciones y fisuraciones, así como de un considerable entumecimiento. Una vez más, los buenos cementos puzolánicos son los más recomendables para el caso, aparte de otras válidas razones de distintos órdenes, pues estos cementos son de los que menor entumecimiento experimentan.

Corolario de lo que precede es que, si bien la causa decisiva del movimiento del bloque parece ser de naturaleza física - en definitiva un empuje por presión hidráulica一, la causa anterior y primera puede ser de índole química y residir en la naturaleza del hormigón y en la del propio cemento.

\subsection{Cementos para presas}

Las mencionadas razones válidas para utilizar en general y preferentemente cementos puzolánicos $-\mathrm{u}$ otros cementos, de tipo portland o no, en determinados casos específicospara los hormigones de presas, emanan de las características y exigencias que presenta este tipo de obra, a saber: resistencia mecánica para aguantar el empuje del agua y resistencia química para oponer a una posible agresıón ácida mineral, carbónica o salina de distintas aguas, según los casos; y también capacidad de retención, es decir, impermeabilidad. Una presa no puede ser, ni un colador, ni una esponja.

En cuanto a la resistencia mecánica, en ningún caso debe constituir un problema, pues a 
tal efecto cualquier tipo de cemento suficientemente resistente puede ser utilizado en principio, con tal de que las condiciones de proyecto, cálculo, otros materiales, dosificación, ejecución, puesta en obra, compactación, curado y control sean cumplidamente las adecuadas.

En cuanto a la resistencia química la cuestion es distinta, ya que pueden surgir problemas, puesto que las aguas muy puras de montaña, las carbónicas agresivas y las ácidas, con gran capacidad de disolución y de ataque, son susceptibles de provocar el deslavado o lixiviación de la cal de hidrólisis del cemento - la portlandita-, dando lugar a un aumento de porosidad y a un debilitamiento del hormigón. Y habida cuenta también de que las aguas salinas, particularmente las sulfatadas, son susceptibles de formar yeso con dicha cal de hidrólisis y ettringita con los aluminatos del cemento, dando pie a reacciones expansivas de estructuras del hormigón, en tales casos no todos los cementos son igualmente aptos y recomendables.

Para mejor resistir los ataques de tipo ácido son más idóneos los cementos puzolánicos, ya que fijan la cal de hidrólisis de forma estable; y para aguantar mejor la agresión salina de los sulfatos, lo son los cementos de bajo contenido de aluminato tricálcico (y de baja suma de aluminato más ferrito) dentro de los portland, los propios cementos puzolánicos y, cómo no, los cementos siderúrgicos.

Por lo que respecta a la capac:dad de retención de agua por parte de una presa, las grietas y fisuras deben estar ausentes del paramento de la misma, como condición necesaria. Para ello son más idóneos los cementos de baja retracción, tanto química -irreversible- como hidráulica y térmica - reversibles (al menos en parte)-. A tal efecto son aptos los cementos de bajos contenidos de aluminato tricálcico y de álcalis, de poca finura y de bajo calor de hidratación. En consecuencia, los cementos puzolánicos que fijan cal dando geles tobermoríticos más silícicos, esto es, de menor relación cal/sílice en su composición, los cuales, por su acción colmatante, rellenan y taponan poros e impermeabilizan en una cierta medida el hormigón, es decir, reducen la penetrabilidad del mismo al agua y a las disoluciones salinas.

En resumen, la conclusión es que, para presas, los cementos más idóneos pueden ser los puzolánicos constituidos por un 30-40 por ciento de una puzolana eminentemente silícica y muy activa, y por un 70-60 por ciento de un clínker con menos de 5 por ciento de aluminato tricálcico (en general, con tanto menor contenido de aluminato tricálcico en el clínker cuanto mayor contenido de alúmina en la puzolana), y menos de 20-22 por ciento de suma de aluminato tricálcico y ferrito-aluminato tetracálcico, que al mismo tiempo fuesen de bajo calor de hidratación (a título orientativo, con menos de 65 calorías/gramo a 7 días y menos de 75 calorías/gramo a 28 días).

\subsection{Cementos para cimentaciones}

Por semejanza, las principales características exigibles a los cementos para este tipo de obras son: resistencia mecánica, resistencia química frente a aguas y suelos agresivos, y estabilidad.

En lo que se refiere a la resistencia mecánica es válido cuanto queda indicado para el caso de las presas, siendo idóneo, en principio, cualquier tipo de cemento. En cuanto a la resistencia química, si por delimitar el problema se cons deran posibles ataques por aguas ácidas y por aguas y suelos yesíferos, los cementos más aptos serían, por orden de eficacia, los puzolánicos con clínker bajo en aluminato y ferrito, y los puzolánicos ordinarios, en el primer caso; y los siderúrgicos en una u otra de sus distintas clases, según la 
naturaleza del medio atacante y el contenido de escoria siderúrgica del cemento. Sin olvidar los posibles cementos ternarios a base de clínker, escoria y puzolana, prácticamente inéditos, pero previsiblemente los más eficaces.

\subsection{Otras expansiones ajenas al cemento}

No hay que perder de vista otros fenómenos de expansión que pueden ser catastróficamente detrimentales para el hormigón, y que no residen en absoluto -o solamente - en el cemento, sino en exclusiva -o además- en los áridos. Tres son los casos más característicos.

\subsubsection{Reacción árido-álcalis}

Una vez más surge este tema del que ya queda dicho algo, especialmente en cuanto a lo que importa respecto del empleo de cementos portland: que deben ser de bajo conten:do de álcalis.

Pero no acaba con ello el problema, pues en la expansión árido-álcalis no intervienen sólo los álcalis del cemento, sino todos los presentes en el hormigón, sea cual fuere su procedencia: los propios áridos, el agua de amasado y los aditivos, en su caso.

Esto, que en la actualidad es generalmente reconocido, aminora la garantía de evitar o atenuar la reacción con el empleo de cementos pobres en álcalis, pues de hecho se han observado expansiones en hormigones con cementos de bajo contenido de álcalis, y no se han observado en otros hormigones con cementos de contenido de álcalis normal e incluso alto.

Sin embargo, no se va a seguir tratando aquí con más detalle de este tema, del cual repito que me consta que es bien conocido en este país y que, por lo tanto, está bajo control.

Unicamente habría que hacer mención de un hecho real, que a primera vista parece paradójico y contradictorio, y que, por lo tanto, requiere una explicación.

El hecho es que, una vez más, los cementos puzolánicos son, también en este caso, uno de los remedios más eficaces para eliminar o reducir los efectos de la expansión por reacción árido-álcalis. $\mathrm{Y}$ esto sucede a pesar de que prácticamente todas las puzolanas naturales - $\mathrm{y}$ sobre todo las más activas - tienen un contenido de álcalis muy superior al del cemento. (No hay que olvidar que entre las mejores puzolanas naturales se cuentan las traquitas alcalinas italianas y españolas).

La explicación consiste en que las puzolanas muy finamente molidas y muy dispersas en los cementos puzolánicos, y por lo tanto también en los hormigones que los contienen, reaccionan con los álcalis del cemento - $\mathrm{y}$, en general, con todos los álcalis presentes en el hormigón-, antes de que lo hagan los componentes reactivos de los áridos.

Con ello se consigue sustituir pocas acciones localizadas y muy intensas, por muchas acciones muy uniformente extendidas y generalizadas, pero muy poco intensas, de tal manera que los efectos de las mismas hacia el exterior (fisuración y rotura del hormigón), o no se producen, o lo hacen en una medida mucho menor, y casi siempre admisible.

En definitiva, el remedio consiste en aplicar el viejo aforismo marcial de "divide y vencerás". o el axioma físico de que "lo que se gana en extensión se pierde en intensidad", lo cual tiene también expresión en un antiguo refrán castellano: "el (o lo) que mucho abarca, poco aprieta". 
Esta explicación es asimismo válida para otro remedio que se suele poner en práctica y con éxito ante la necesidad ineludible de utilizar áridos reactivos: el de mezclar con el cemento $-\mathrm{y}$ en el hormigón-, y molida a un grado de finura análogo al del cemento, una determinada proporción del propio árido reactivo que haya de ser empleado.

Todo esto es así porque la acción nociva y el consiguiente efecto pernicioso de la reacción árido-álcalis es muy localizada - casi puntual y en relativamente pocos puntos-, como lo prueba la fisuración "en mapa" que se observa en la superficie del hormigón, la cual presenta fisuras que forman, en general, ángulos de 120 grados — de tres en tres, a partir de un mismo punto-, y que se entrecruzan entre sí.

Esto es indicio de una acción expansiva de dentro hacia afuera, a partir de puntos o "hipocentros" de la masa del hormigón - las partes de los áridos en las que se localizan los minerales susceptibles de reaccionar con los álcalis-, y que "punzona" hacia la superficie del material, manifestándose en los correspondientes "epicentros", a partir de los cuales se extienden las fisuras a 120 grados unas con otras.

\subsubsection{Expansión de áridos piritosos}

Hay otro tipo de expansión demoledora, proveniente en exclusiva de los áridos, la cual se manifiesta por fisuraciones y agrietamientos del hormigón, por pérdidas de adherencia entre éste y sus armaduras, y por la corrosión posterior de éstas.

Estos hechos se deben a la presencia, en determinados áridos, de algunos sulfuros metálicos, particularmente de hierro, como las piritas, la pirrotita y la marcasita, los cuales pueden experimentar una oxidación, a veces rápida, y con carácter expansivo y disruptivo.

En la oxidación los sulfuros pasan a sulfatos y los iones ferrosos pasan en parte a férricos, hidratándose unos y otros y formando oxi-hidróxidos ferroso-férricos (es decir, herrumbre expansiva análoga a la que se genera en la corrosión de las armaduras), la cual provoca las fisuras y disminuye peligrosamente la capacidad resistente del hormigón.

El que les habla ha tenido ocasión de saber de treinta casos de edificios afectados, al cabo de un año y medio de ser construidos, por grietas anchas y profundas, tanto horizontales como verticales, en forjados y en cabezas de pilares, habiendo sido preciso demoler lo construido al cabo de los dos años y medio, ante el incremento de las grietas.

Uln hecho singular y curioso es que, en estos casos en los que se produjo el agrietamiento por oxidación de áridos piritosos en forjados, dicho agrietamiento tuvo lugar en forma y con apariencia "de estrella", al decir de quienes lo describieron, lo cual lleva a recordar las fisuraciones "en mapa" de la expansión por reacción árido-álcalis. Esto no deja de tener un sentido y una lógica, pues de causas y mecanismos análogos hay que esperar análogos efectos y manifestaciones.

Lo peor del asunto fue, en su momento, el desconocimiento inicial del número total de casos implicados en el uso de tales áridos insanos durante unos diez años, los cuales procedían de una zona de nueva explotación, en una cantera que tradicionalmente se venía explotando sin inconvenientes.

La enseñanza deducible de estos hechos es que no basta con ejercer un cómodo y fácil control del cemento en las obras, sino que este control es preciso hacerlo extensivo también 
al resto de los materiales del hormigón, y en particular a los áridos, que lejos de ser siempre inertes, a veces son perjudicialmente activos de una u otra forma.

\subsubsection{Expansión por corrosión de armaduras}

La formación de herrumbre por corrosión de armaduras puede afectar a la adherencia acero-hormigón, reducir la sección de las armaduras —e incluso romperlas-, con disminución de la capacidad resistente del hormigón armado o pretensado.

También puede producir fisuras por las que penetren con facilidad agentes agresivos o corrosivos que intensifiquen y aceleren todas estas acciones negativas (esquema 32).

De todo ello habría que tratar de forma muy específica, extensa y detallada, como ya en una ocasión hizo en esta misma ciudad el que les habla. Pero no en este momento.

\section{LA RETRACCION PLASTICA}

Es un nuevo motivo de inestabilidad, esta vez del hormigón fresco.

Por retracción plástica se quiere entender aquí la contracción que experimenta el hormigón una vez puesto en obra y durante su fraguado, es decir, en el período plástico del mäterial.

En general esta retracción plástica se produce por una fuerte y rápida desecación del hormigón, primero superficial y después masiva. El resultado es una fisuración, mucho más intensa y localizada que extensa y difusa, la cual acaba produciendo el agrietamiento profundo del hormigón.

Favorecen este tipo de retracción y fisuración diversos factores, unos externos al hormigón como material, y otros propios de él.

Entre los primeros se cuenta, en primer lugar, el tipo de elemento estructural, viéndose propiciada la retracción plástica en elementos de gran superficie y relativamente pequeño espesor, preferentemente situados en horizontal — como es el caso de los forjados de piso y el de las losas de pavimentación-. en los cuales la desecación por evaporación puede ser muy rápida.

En segundo lugar, las condiciones climáticas, estacionales y ambientales en general pueden favorecer también esta modalidad de retracción. Así, por ejemplo, un forjado a la intemperie se desecará mucho más rápida y profundamente si está sometido a una fuerte insolación y a la acc:ón de un viento seco en un ambiente de baja humedad relativa del aire, que si las condiciones son las contrarias, puesto que en las primeras la evaporación del agua del hormigón es mucho más fácil e intensa. En íntima relación con esto están también las condiciones de curado del hormigón en las primeras horas, como factor ajeno al material, pero inherente a su tecnología.

En cuanto a los factores relativos al propio hormigón, son decisivos los que se refieren a la cantidad de pasta cementante del material —es decir, a su dosificación en kilogramos de cemento por metro cúbico- y, dentro de ello, a la cantidad de agua en la misma - esto es, a la relación agua/cemento-. Y también a la propia docilidad y plasticidad del hormigón y al mantenimiento de esta última en el tiempo, lo cual depende de la capacidad de retención del agua por parte de la pasta. Esto a su vez, depende de la naturaleza del 
cemento y principalmente de su composición y de su finura, o, por mejor decir, de su curva granulométrica.

De la composición del cemento, porque no todos los tipos de ellos tienen el mismo grado de "acritud" en estado anhidro, es decir, en polvo seco, ni dan lugar a pastas con el mismo grado de plasticidad y cohesión en húmedo, tanto en vías de hidratación como en estado hidratado.

Por ejemplo: si se toman como referencia los cementos de tipo portland -constituidos exclusivamente por mezclas de clínker y yeso-, molidos a las finuras usuales, los cementos siderúrgicos - clínker más yeso más escoria de horno alto en distintas proporcionessuelen ser, en general, más "agrios", dado que la escoria suele ser también más dura que el clínker y se refina peor, a pesar de lo cual estos cementos pueden y hasta deben ser más finos que los portland. En consecuencia, es posible que, a igualdad de peso, los cementos siderúrgicos exijan, con relación a los portland, una mayor cantidad de agua para conseguir una pasta de la misma consistencia; pero es posible también que las pastas de los cementos siderúrgicos retengan el agua peor que las de los cementos portland, siendo aquéllos más susceptibles que éstos de dar lugar a exudaciones y rezumados de agua.

Por el contrario, los cementos puzolánicos en general —clínker más yeso más puzolana natural o ceniza volante-, suelen ser menos agrios que los portland (al menos los que contienen puzolanas naturales de igual o menor dureza que el clínker) y, aunque molidos siempre a mayor finura que los portland, a igualdad de peso no siempre exigen una cantidad de agua mayor, para pastas de igual consistencia. De cualquier modo estas pastas poseen generalmente una mayor capacidad de retención del agua en el caso de los cementos puzolánicos que en el de los portland, y son menos propensas a exudar y a hacer rezumar el agua.

En definitiva, se podría pensar que, tomados los cementos portland como referencia, los cementos siderúrgicos serían -en general- más proclives a dar hormigones con tendencia a retracciones y agrietamientos plásticos, mientras que los cementos puzolánicos — $€ n$ general- serían menos propensos a tales acciones y efectos.

Pero más importante que todo esto, aunque ligado a ello como se ha visto, es la finura del cemento -cualquiera que éste sea-; no expresada por uno o dos parámetros (residuos sobre dos tamices o superficie específica), sino representada en su totalidad por la curva granulométrica (esquema 33).

En efecto, el ideal de los cementos compuestos, -es decir, con constituyentes secundarios o adiciones activas (escorias siderúrgicas o puzolanas)-, parece ser que la parte de adición sea más fina que la parte de clínker, por razones obvias, aunque sin rebasar ciertos límites. En tales condiciones la exigencia de agua por parte de los cementos es menor y su retención mayor, obteniéndose pastas y hormigones más plásticos y más dóciles, evitándose la exudación del agua excedente y con ella la retracción plástica y el agrietamiento. Pero si por azar o por alguna otra causa bien determinada y conocida sucediera lo contrario, esto es, que la parte del clínker fuese más fina que la de la adición, podrían resultar cementos que, exigiendo a igualdad de peso una mayor cantidad de agua para una consistencia dada - mayor relación agua/cemento en pasta y en hormigón-, no serían capaces de retener el exceso de agua - no necesario para la hidratación-, el cual rezumaría hacia la parte externa (superior, superficie libre) del hormigón y, al evaporarse rápidamente en las condiciones ambientales propicias antes señaladas, daría lugar a la retracción plástica y al agrietamiento del hormigón (esquema 34).

Esta es, en realidad, lo que ha sucedido en algún caso conocido por el que habla, en el que, pretendiendo aprovechar como "puzolanas" ciertas rocas de tipo ofítico (doleritas, diaba- 
sas, etc.), algunas de gran dureza - $\mathrm{y}$ en todo caso bastante mayor que la dureza del clínker-, estas rocas quedaban más gruesas que el clínker en los cementos correspondientes, con los resultados granulométricos contrarios a los convenientes y deseados. En estas condiciones la exigencia de agua es mayor y la retención de la misma menor, con más abundante exudación y consiguiente retracción y agrietamiento plásticos.

La prueba experimental - y real en la práctica - de todo esto, así como de la influencia decisiva de la desecación rápida, la da una sencilla experiencia, consistente en lo que se expone a continuación. De dos losas de pavimento de un mismo hormigón, adyacentes, una se abandona a un curado espontáneo (o cuidado, según los casos), mientras que la otra se somete a unas condiciones de curado adversas en demasía: desecación forzada y continuada por aire seco y caliente, soplado.

El resultado es que la losa de curado normai o esmerado, no sometida al viento seco no se agrieta, mientras que en la sometida a desecación las grietas se producen ya a la hora y media de hormigonada, aumentando éstas en número, anchura y profundidad hasta las tres horas, tiempo en el que las grietas parecen estabilizarse. La anchura de las grietas llega a ser de varios milímetros - tres- en la cara superior de la losa, y su profundidad llega a afectar a todo el espesor de la misma -26 centímetros- (esquema 35 tomado de J. I. MARTINEZ YNZENGA y M. AGUANELL: "Ensayo a escala de obra sobre fisuración y agrietamiento". Materiales de Construcción - IETCC, núm. 168, pág. 27, octubre-noviembre-diciembre (1977).

Esto se produce con independencia del tipo de cemento del hormigón, influyendo más la temperatura ambiente y, sobre todo, el grado de humedad relativa del aire soplado sobre la losa aireada; pero, evidentemente, el fenómeno es favorecido, como se pudo comprobar sin lugar a dudas, por la mayor exigencia de agua del cemento y por la menor capacidad de retención del agua por parte del mismo, o, lo que es igual, por su mayor tendencia a la exudación y al rezumado. Entre tales cementos, por unos que contenían una supuesta adición puzolánica en proporción del orden del 20 por ciento, consistente en un material ofítico duro.

A continuación de la retracción plástica del hormigón fresco puede tener lugar la retracción hidráulica del hormigón ya endurecido. Es evidente que en ésta, y en la fisuración a la que pudiera dar lugar, influye también la temperatura y el estado higrométrico del aire. En cuanto a la influencia del tipo de cemento en el hormigón, a igualdad de todo lo demás, la cosa es más complicada.

En efecto, se podría pensar que el comportamiento (relativo) de los cementos en este aspecto se podría determinar mediante el ensayo francés del anillo de pasta pura. Pero este ensayo, de medir algo, sería la "fisurabilidad" de la pasta de cemento, y no la tendencia del cemento a la retracción, como en alguna ocasión se ha pretendido, pues, por una parte, el ensayo consiste en medir el tiempo transcurrido hasta la aparición de la primera fisura en unas condiciones dadas; y, por otra parte, la retracción no es sino un factor de la fisuración, la cual depende además de la resistencia a la tracción y del módulo de elasticidad —o si se prefiere de la deformabilidad e indeformabilidad- del material.

Al influir solidaria e indisolublemente estos tres factores en la fisuración, en forma no bien precisa, y con resultados de laboratorio difíciles de correlacionar con los comportamientos reales de los cementos en la práctica, el método no es muy de fiar, por lo cual los propios franceses que lo inventaron lo han abandonado, incluso como procedimiento de medir la "fisurabilidad". 


\section{FINAL}

A lo largo de lo que precede se han hecho tantas alusiones a la idoneidad de los cementos puzolánicos y siderúrgicos en tantos aspectos, que el conjunto de ellas podría parecer una apología de dichos cementos. Realmente lo es en la medida en que puede y debe serlo (esquemas 36 y 37 ).

Pero, aparte de las ventajas técnicas que en multitud de casos bien definidos puede tener el empleo de tales cementos frente al de los cementos portland, con miras al hormigón, hay también ventajas de otros órdenes. Por ejemplo, el aprovechamiento de subproducios que poseen un contenido energético potencial -escorias, puzolanas, cenizas volan. tes-, y cuya eliminación por otras vías lo desperdic:a, aparte de implicar un gasto adicional.

Paralelo a este aprovechamiento corre el ahorro de energía - combustible (fuel-oil) - en la fabricación del cemento, si se tiene en cuenta que cada tonelada producida exige, grosso modo, el consumo de 100 kilogramos de fuel-oil, y que la sustitución de clínker por materiales que no pasan por el horno reduce el consumo de combustible, también grosso modo, en la misma cuantía porcentual de dicha sustitución. También en molienda se puede bajar de $100 \mathrm{kwh} / \mathrm{t}$, que es un consumo normal tirando a bajo.

Y por fin, ecológicamente considerada, la eliminación rentable de escombreras — de cenizas o de escorias- contribuye a la conservación del paisaje.

Mucho más daría de sí el tema de la dependencia entre las características de los cementos y las propiedades y el comportamiento de los hormigones, enfocado sobre todo en el aspecto de la elección de los cementos más idóneos en cada caso. Y más ejemplos se podrían poner de lo acertado o erróneo de utilizar unos u otros cementos en determinadas circunstancias.

No obstante, se juzga que las razones y los ejemplos prácticos reales expuestos son suficientemente típicos y representativos, así como de fácil generalización y extrapolación a casos semejantes o parecidos. De cualquier modo, de otros ejemplos y de otros casos se puede tratar, si se estima oportuno, en coloquio, mientras el tiempo disponible lo permita.

Si con todo ello se contribuye de cierta manera y en cierta medida a despertar o reforzar el interés por un tema que se juzga importante, el expositor considerará que ha cumplido discretamente con el fin que se proponía.

Es todo. Muchas gracias.

\section{R E F E R E N C I A S}

(1) Calleja, J.: "Código de Buena Práctica para la Utilización de los Cementos del Pliego RC-75". Manuales y Normas del IETCC, Madrid, 1976.

(2) RC-75: "Pliego de Prescripciones Técnicas Generales para la Recepción de Cementos". Ministerio de Obras Públicas y Urbanismo, Secretaria General Técnica, Servicio de Publicaciones, Madrid, 1975. 


\section{ESQUE MAS}




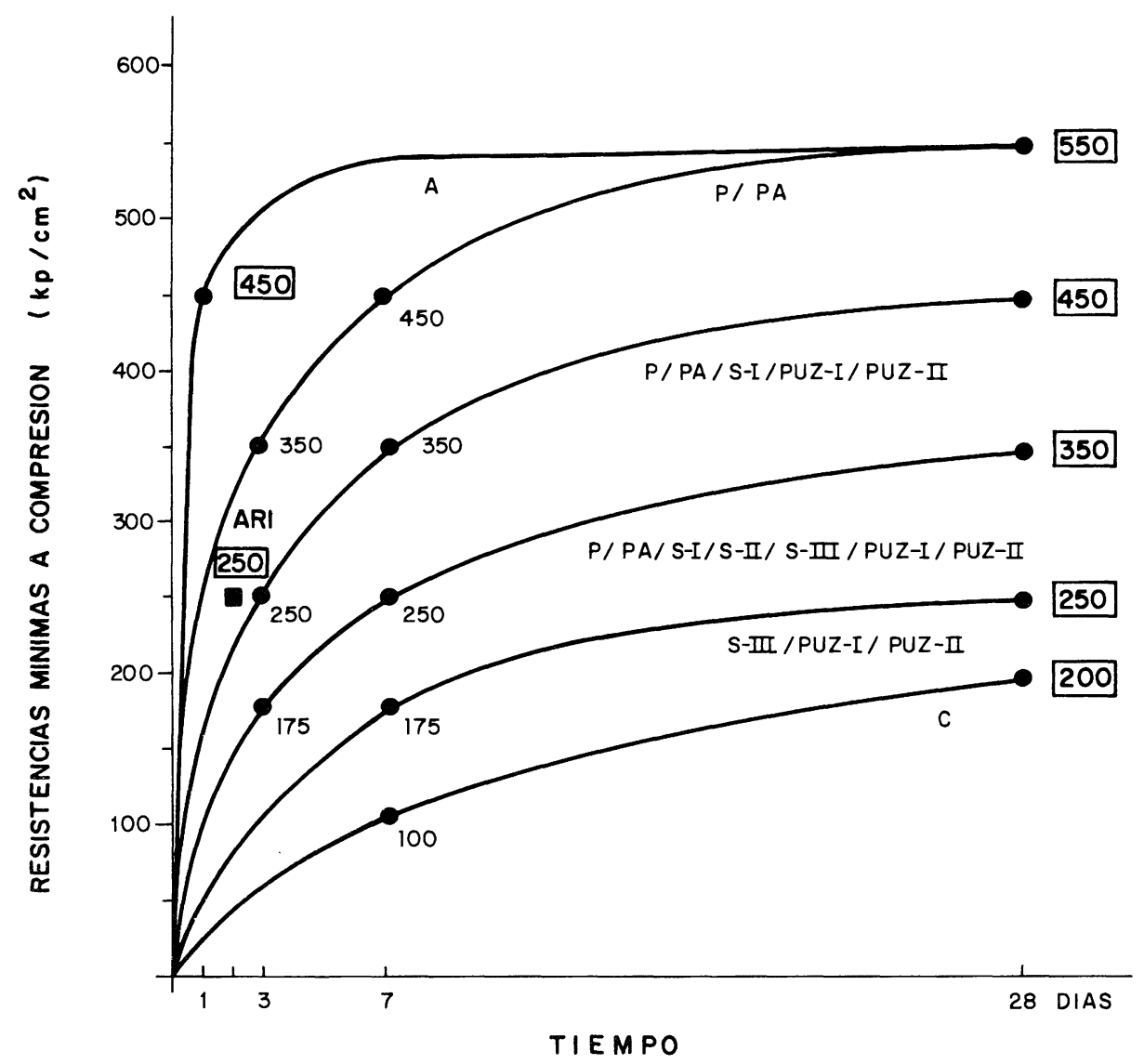

ESQLEMA 1

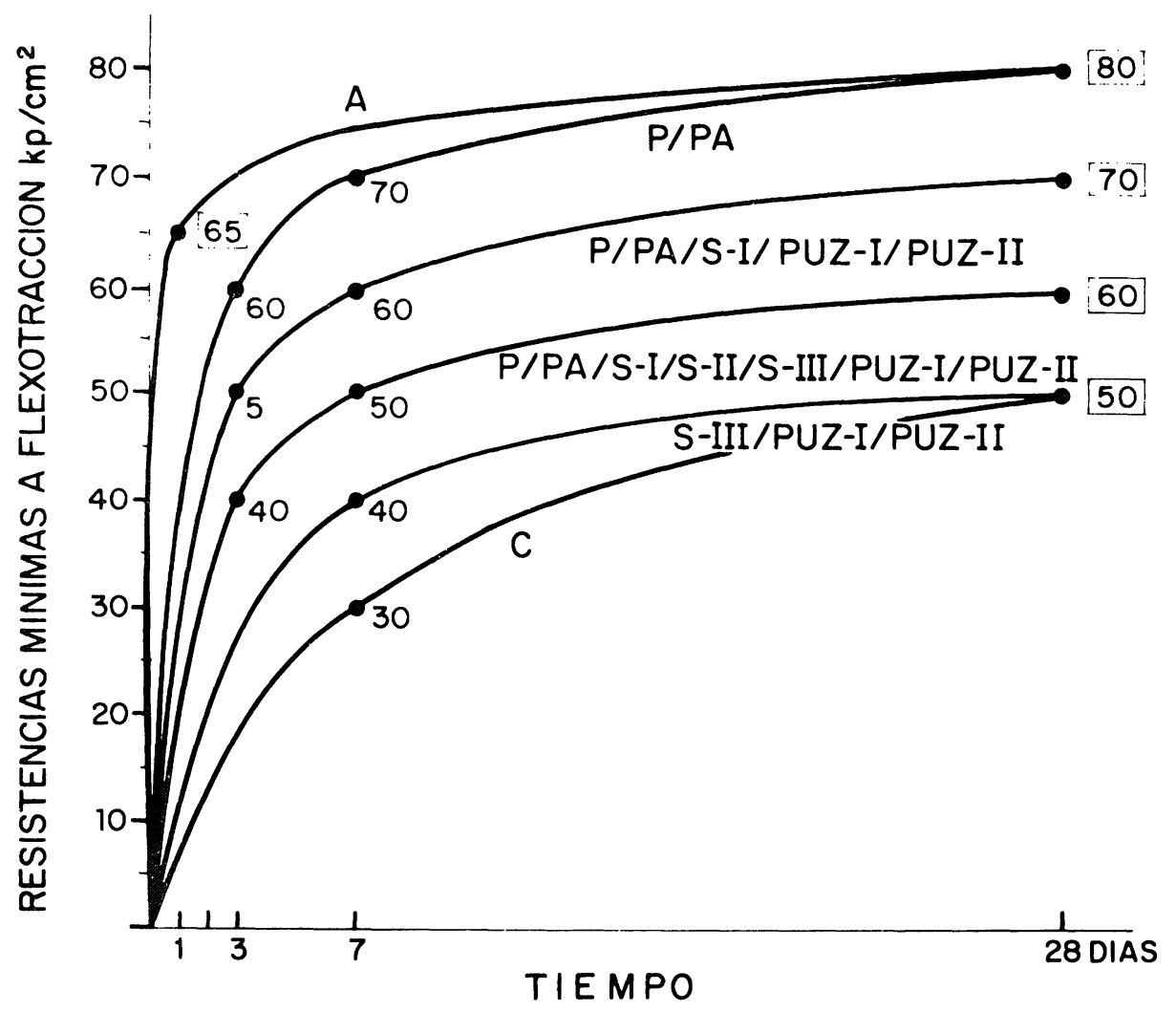

NSQEEMA 2 


\section{COMPONENTES Y CONSTITUYENTES DEL CEMENTO}

NOMENCLATURA

Componentes(óxidos)

Oxido cálcico

Anhidrido silicico

Oxido aluminico (alúmina)

Oxido férrico

Trióxido de azufre

Aguo

Constifuyentes

(espocies quimicas)

Silicato tricálcico

Silicoto bicolicico

Aluminato tricólcico

Ferrito-cluminoto tetrocócicico

Sutfoto celicico

dinidroto (yeso)
FORMULACION

$\mathrm{CaO}$

$\mathrm{SiO}_{2}$

$\mathrm{Al}_{2} \mathrm{O}_{3}$

$\mathrm{Fe}_{2} \mathrm{O}_{3}$

$\mathrm{SO}_{3}$

$\mathrm{H}_{2} \mathrm{O}$

$3 \mathrm{CaO} \mathrm{SiO}_{2}$

$2 \mathrm{CaO} \mathrm{SiO}_{2}$

$3 \mathrm{CaO} . \mathrm{Al}_{2} \mathrm{O}_{3}$

$4 \mathrm{CoO} . \mathrm{Al}_{2} \mathrm{O}_{3} \mathrm{Fe}_{2} \mathrm{O}_{3}$

$\mathrm{CaSO}_{4} .2 \mathrm{H}_{2} \mathrm{O}$
FORMULA ABREVADA

C

s

A

$F$

8

H

$\mathrm{C}_{3} \mathrm{~S}$

$\mathrm{C}_{2} \mathrm{~S}$

$\mathrm{C}_{3} \mathrm{~A}$

$C_{4} A F$

$\mathrm{Cs}_{2}$

\section{CLINKER :}

Silicatos \%

75 Tricálcico $\mathrm{SC}_{3} \% \quad 50$ Bicálcico $\quad \mathrm{SC}_{2} \% \quad 25$

Aluminatos y Ferritos \% 20 Aluminatos $A C_{3} \% \quad 10$ Ferrito $\mathrm{FAC}_{4} \% \quad 10$

Resto \%

5 Resto \% 5

TOTAL \% 100 100

\begin{tabular}{llr} 
Resto \% 5 & $\begin{array}{l}\text { Cal libre \% } \\
\text { Magnesia \% }\end{array}$ & 1 \\
& Compuestos & alcalinos \% 2 \\
\hline TOTAL \% 5 & & 5
\end{tabular}


Silicato tricálcico:

Silicato bicálcico:

Aluminato tricálcico:

Ferrito-aluminato tetracálcico: de 0 a $20 \%$

Cal libre:

Magnesia :

Compuestos alcalinos: de 30 a $60 \%$ de 20 a $40 \%$ de 0 a $15 \%$ de 0 a $2 \%$ de 1 a $4 \%$ de 0,5 a $2,5 \%$

ESQLEMA :

CEMENTO PORTLAND :

Clínker \% $\quad 95$ Silicatos $\% 71,25 \sim 70 \quad$ Tricálcico $\% 47,50 \sim 45$

Bicálcico \% 23,75 25

Aluminatos $\quad$ Aluminatos $\% 9,50 \sim 10$

y $19,00 \sim 20$

Ferritos $\% \quad$ Ferritos $\% \quad 9,50 \sim 10$

Resto $\quad \% \quad 4,75 \sim 5$ Cal libre $\% \quad 0,95 \sim 1$

Magnesia $\% \quad 1,90 \sim 2$

Alcalis $\% 1,90 \sim 2$

Sulfato cálcico \% 5 $5,00=5$

TOTAL $\quad 100$

$5,00=5$

$100,00 \quad 100$




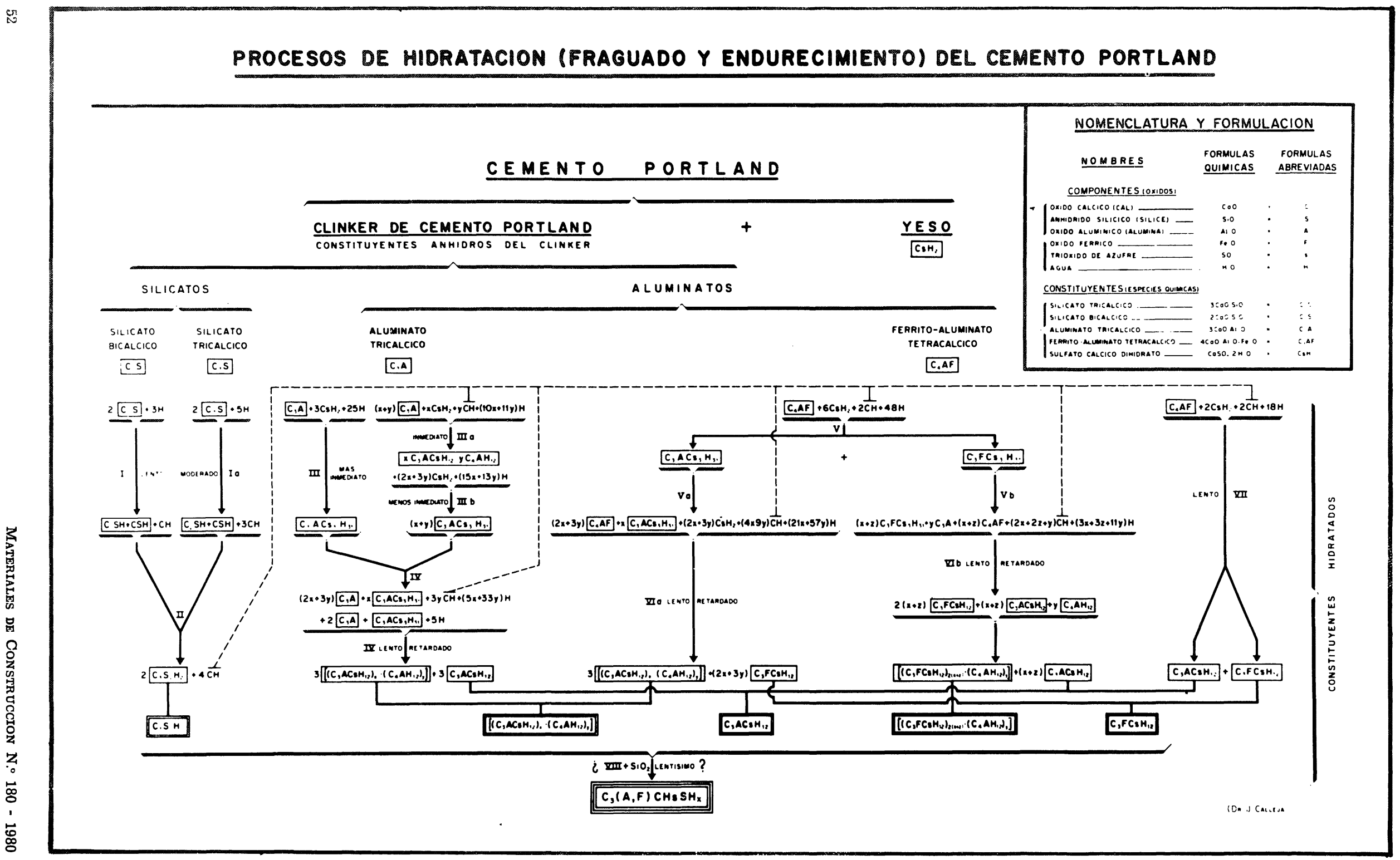

ESQLEMA : 


\section{PARAMETROS PRINCIPALES DE LA HIDRATACION}

I Velocidad de hidratación.

2 Calor de hidratación.

I) Calor total desprendido.

II) Velocidad de desprendimiento.

3 Estabilidad de volumen.

4 Estabilidad quimica (durabilidad).

ESQLEMA 8

\section{CEMENTOS PORTLAND}

Ricos en $\mathrm{SC}_{3}: 60 \%$

(Pobres en $\mathrm{SC}_{2}: 20 \%$ )

+ más rasistentes

- más fisurables

- más atacables

+ más protectores (de armaduras)
Pobres en $\mathrm{SC}_{3}: 30 \%$

(Ricos en $\mathrm{SC}_{2}: 40 \%$ )

- menos protectores (de armaduras)

+ menos atacables

+ menos fisurables

- menos resistentes 


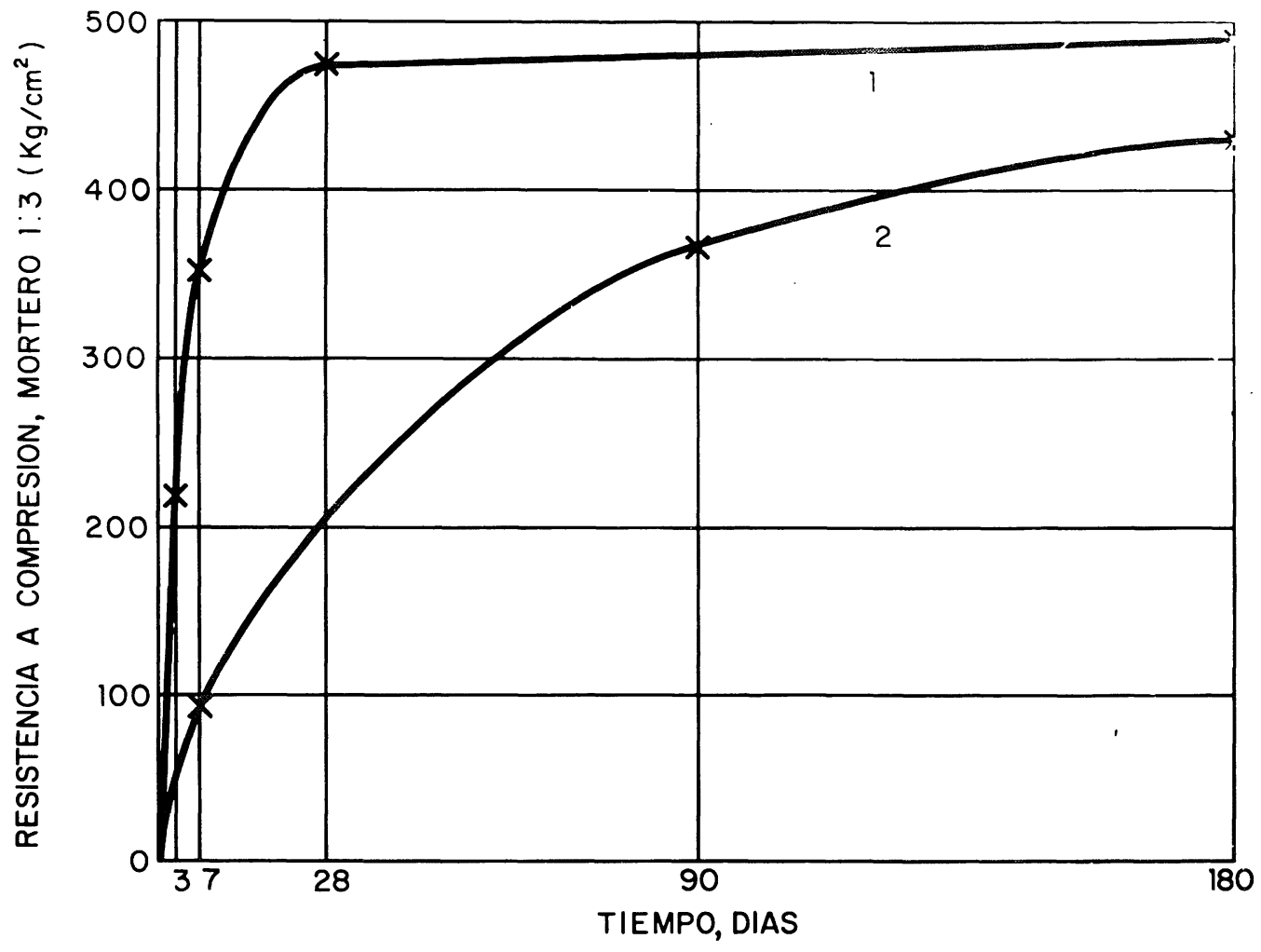

1.- $70 \% 3 \mathrm{CaO} . \mathrm{SiO}_{2} ; 10 \% 2 \mathrm{CaO} . \mathrm{SiO}_{2}$

2. $-30 \% 3 \mathrm{CaO} . \mathrm{SiO}_{2} ; 50 \% 2 \mathrm{CaO} . \mathrm{SiO}_{2}$

\section{HIDRATACION DE LOS SILICATOS}

$C_{3} s$

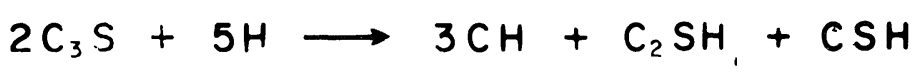

$\zeta$

(HILLEBRANDITA)(TOBERMORITA)

$2 \mathrm{C} . \mathrm{S}+5 \mathrm{H} \longrightarrow 3 \mathrm{CH}+\mathrm{C}_{3} \mathrm{~S}_{2} \mathrm{H}_{2}$

(AF WILLITA)

$C_{2} S \begin{cases}2 \mathrm{C}_{2} \mathrm{~S}+3 \mathrm{H} \longrightarrow \mathrm{CH} & +\mathrm{C}_{2} \mathrm{SH}+\mathrm{CSH} \\ 2 \mathrm{C}_{2} \mathrm{~S}+3 \mathrm{H} \longrightarrow \mathrm{CH}+\mathrm{C}_{3} \mathrm{~S}_{2} \mathrm{H}_{2} & \underbrace{\longrightarrow}_{\text {(HILLEBRANDITA)(TOB }}\end{cases}$

(AFWILLITA) 


\section{CEMENTOS PORTLAND}

Ricos en $\mathrm{AC}_{3}: 15 \%$

(Pobres en $\mathrm{FAC}_{4}: 5 \%$ )

- más atacables

- mayor retracción

\pm mayor calor de hidratación
Pobres en $\mathrm{AC}_{3}: 5 \%$

(Ricos en $\mathrm{FAC}_{4}: 20 \%$ )

$\mp$ menor calor de hidratación

+ menor retracción

+ menos atacables

ESQUEMA 12

\section{HIDRATACION DE LOS ALUMINATOS}

$$
\underline{\mathrm{C}_{3} \mathrm{~A}}
$$

$(3 x+y+z) \mathrm{C}_{3} \mathrm{~A}+(3 x+y) \mathrm{CsH}_{2}+z \mathrm{CH}+(30 \mathrm{x}+10 \mathrm{y}+11 z) \mathrm{H} \rightarrow 3 \mathrm{CC}_{3} \mathrm{ACsH}_{12}+\left(\mathrm{C}_{3} \mathrm{ACsH} \mathrm{H}_{12}\right)_{y} \cdot\left(\mathrm{C}_{4} \mathrm{AH}_{12}\right)_{z}$

$$
\underline{C_{4} A F}
$$

$(3 x+3 y+z) C_{4} A F+(18 x+12 y+2 z) C_{s} H_{2}+(6 x+5 y+2 z) C H+(144 x+109 y+18 z) H \rightarrow$

$=3 \times C_{3} A C s_{3} H_{31}+3 \times C_{3} \mathrm{FCs}_{3} \mathrm{H}_{31}+\left(\mathrm{C}_{3} A \mathrm{ACs}_{3} \mathrm{H}_{31}\right)_{y} \cdot\left(\mathrm{C}_{3} \mathrm{FCs}_{3} \mathrm{H}_{31}\right)_{3 y}+z \mathrm{C}_{3} \mathrm{ACs} \mathrm{H}_{12}+\mathrm{ZC}_{3} \mathrm{FCsH}_{12}+y \mathrm{C}_{2} A \mathrm{H}_{8}+y \mathrm{C}_{3} A \mathrm{H}_{6}$ 


\section{COMPORTAMIENTO DE LOS CONSTITUYENTES}

\section{PRINCIPALES DEL CEMENTO PORTLAND}

\begin{tabular}{|l|c|c|c|c|}
\hline \multicolumn{1}{|c|}{ CONSTITUYENTE } & $\begin{array}{c}\text { VELOCIDAD DE } \\
\text { HIDRATACION }\end{array}$ & $\begin{array}{c}\text { CALOR DE } \\
\text { HIDRATACION }\end{array}$ & $\begin{array}{c}\text { DESARROLLO DE } \\
\text { RESISTENCIAS }\end{array}$ & $\begin{array}{c}\text { DURABILIDAD } \\
\text { QUIMICA }\end{array}$ \\
\hline SILICATO TRICALCICO & GRANDE & $\begin{array}{c}\text { GRANDE Y RAPIDO } \\
120 \mathrm{cal} / \mathrm{gr} .\end{array}$ & $\begin{array}{r}\text { RAPIDO Y } \\
\text { PROLONGADO }\end{array}$ & PEQUEÑA \\
\hline SILICATO BICALCICO & PEQUEÑA & $\begin{array}{c}\text { PEQUEÑO Y LENTO } \\
62 \text { col/gr. }\end{array}$ & $\begin{array}{c}\text { LENTO Y MUY } \\
\text { PROLONGADO }\end{array}$ & INTERMEDIA \\
\hline ALUMINATO TRICALCICO & MUY GRANDE & $\begin{array}{c}\text { MUY GRANDE Y RAPIDO } \\
207 \text { cal/gr. }\end{array}$ & $\begin{array}{c}\text { MUY RAPIDO Y } \\
\text { CORTA DURACION }\end{array}$ & MUY PEQUENAA \\
\hline $\begin{array}{l}\text { FERRITOALUMINATO TE- } \\
\text { TRACALCICO }\end{array}$ & GRANDE & $\begin{array}{c}\text { MODERADO Y LENTO } \\
100 \text { col/gr. }\end{array}$ & POCO CONOCIDO & GRANDE \\
\hline
\end{tabular}

ESQCEMA 14

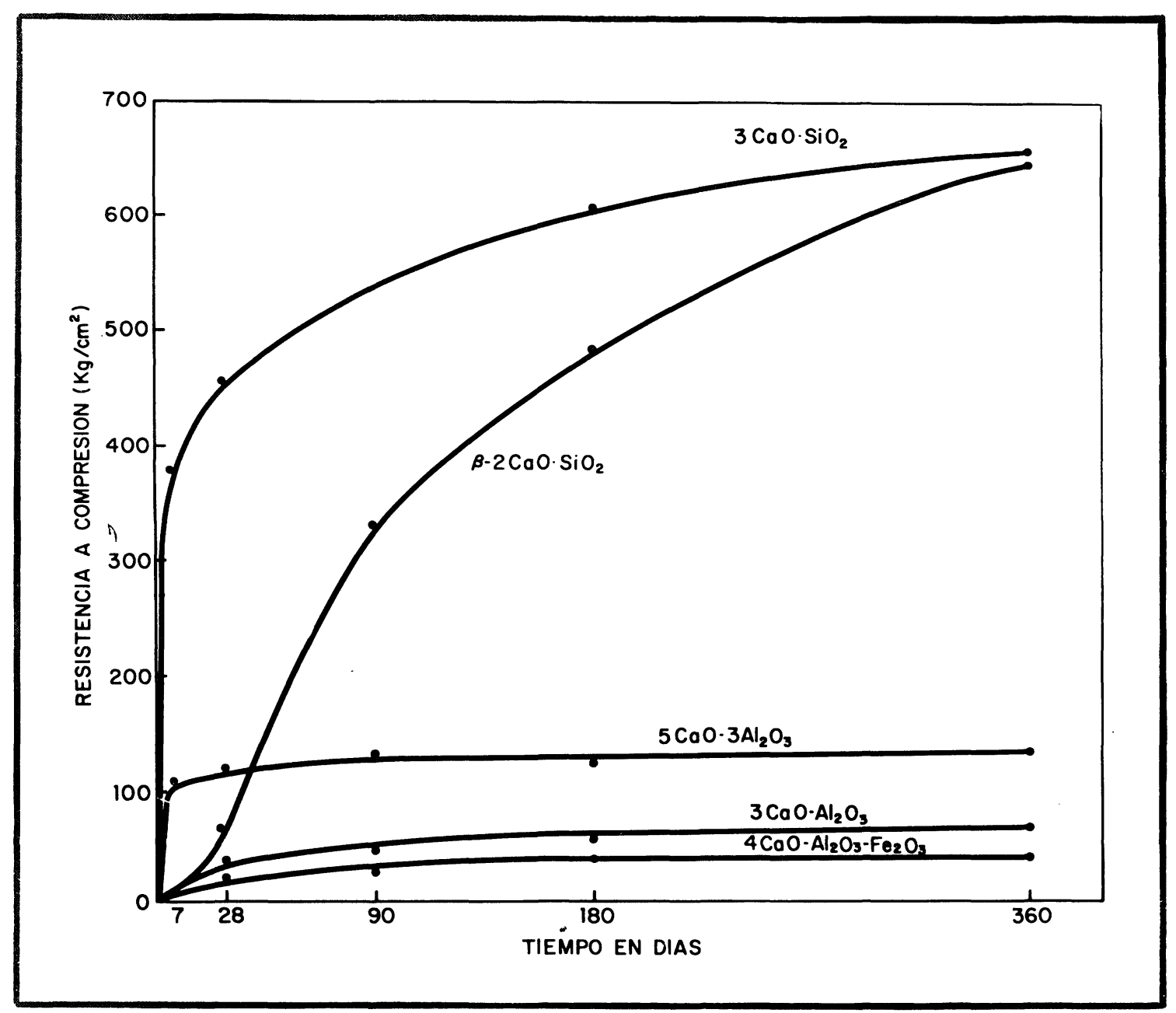

ESQUEMA 15 


\begin{tabular}{|c|c|c|c|c|c|c|c|c|c|c|c|}
\hline $\begin{array}{l}\frac{\pi}{3} \\
\frac{5}{2} \\
0\end{array}$ & $\begin{array}{l}\alpha \\
\mathbb{8} \\
0 \\
0\end{array}$ & $\begin{array}{l}\frac{D}{n} \\
\frac{0}{n}\end{array}$ & $\begin{array}{l}3 \\
0 \\
0\end{array}$ & $\begin{array}{l}? \\
0 \\
0 \\
?\end{array}$ & ${ }_{\infty}^{\pi}$ & $\underset{\omega}{D}$ & $\tilde{N}^{\sim}$ & $\stackrel{\omega}{\omega}$ & $\vec{v}$ & & $\begin{array}{l}\text { CONSTITU- } \\
\text { YENTES } \\
\text { DEL } \\
\text { CEMENTO } \\
\text { PORTLAND }\end{array}$ \\
\hline$V$ & V & $\Lambda$ & $\Lambda$ & $\Lambda$ & $\Lambda$ & V & $\Lambda$ & V & \pm & 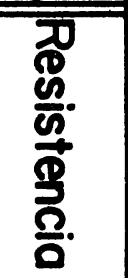 & \\
\hline$\Lambda$ & V & V & V & V & $\Lambda$ & V & I & 1 & I & 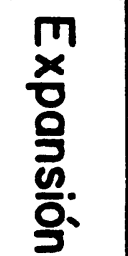 & $D_{D}^{D}$ \\
\hline$V$ & $\Lambda$ & 1 & $\Lambda$ & $\Lambda$ & $\Lambda$ & V & $\Lambda$ & V & $T$ & 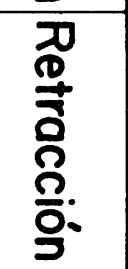 & $\frac{\pi}{\frac{1}{\pi}}$ \\
\hline V & $\Lambda$ & 1 & $\Lambda$ & $\Lambda$ & $\Lambda$ & V & $\Lambda$ & V & 1 & 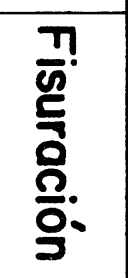 & $\frac{1}{\Omega}$ \\
\hline$\Lambda$ & $\Lambda V$ & $\Lambda$ & $\Lambda$ & $\Lambda$ & V & $\Lambda$ & V & $\Lambda$ & \pm & 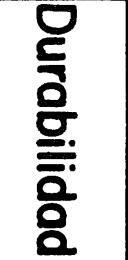 & $\frac{\Gamma}{\Gamma}$ \\
\hline V & 1 & $\Lambda V$ & 1 & $\Lambda$ & 1 & 1 & V & $\Lambda$ & I & 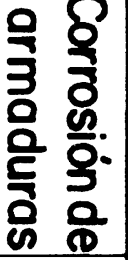 & 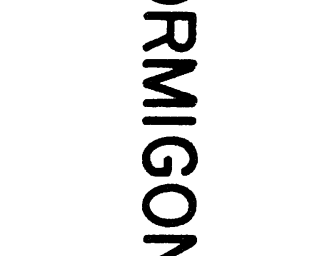 \\
\hline V & $\Lambda$ & $\Lambda$ & $\Lambda$ & V & $\Lambda$ & V & $\Lambda$ & V & $\tilde{+1}$ & 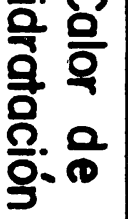 & \\
\hline
\end{tabular}




$$
\begin{aligned}
& \text { SISTEMA } C-S-A-F \\
& \left(C_{3} S-C_{2} S-C_{3} A-C_{4} A F\right) \\
& \text { NORMAL } \\
& \underline{A} / F \geqslant 0,64 \\
& \mathrm{C}_{3} \mathrm{~S}=4,07 \mathrm{CaO}-\left(7,60 \mathrm{SiO}_{2}+6,72 \mathrm{Al}_{2} \mathrm{O}_{3}+1,43 \mathrm{Fe}_{2} \mathrm{O}_{3}+2,85 \mathrm{SO}_{3}\right) \\
& \mathrm{C}_{2} \mathrm{~S}=2,87 \mathrm{SiO}_{2}-0,754 \mathrm{C}_{3} \mathrm{~S} \\
& \mathrm{C}_{3} \mathrm{~A}=2,65 \mathrm{Al}_{2} \mathrm{O}_{3}-1,69 \mathrm{Fe}_{2} \mathrm{O}_{3} \\
& \mathrm{C}_{4} \mathrm{AF}=3.04 \mathrm{Fe}_{2} \mathrm{O}_{3} \\
& \text { Si } A / F=0,64, \quad C_{3} A=0 \\
& \underline{A} / \mathrm{F}<0,64 \\
& \mathrm{C}_{3} \mathrm{~S}=4,07 \mathrm{CaO}-\left(7,60 \mathrm{SiO}_{2}-4,48 \mathrm{Al}_{2} \mathrm{O}_{3}-2,86 \mathrm{Fe}_{2} \mathrm{O}_{3}-\underline{2,85 \mathrm{SO}_{3}}\right) \text {. } \\
& \mathrm{C}_{2} \mathrm{~S}=2.87 \mathrm{SiO}_{2}-0.754 \mathrm{C}_{3} \mathrm{~S} \\
& \mathrm{C}_{4} \mathrm{AF}+\mathrm{C}_{2} \mathrm{~F}=2,10 \mathrm{Al}_{2} \mathrm{O}_{3}+1,70 \mathrm{Fe}_{2} \mathrm{O}_{3}
\end{aligned}
$$

ESQUEMA 17

$$
\begin{gathered}
\text { SISTEMA } C-S-A-F \\
\left(C_{3} S-C_{3} A-C_{4} A F-C\right) \\
\text { RICO EN CAL }
\end{gathered}
$$

$\mathrm{C}_{3} \mathrm{~S}=3,80 \mathrm{SiO}_{2}$

$\mathrm{C}_{3} \mathrm{~A}=2.65 \mathrm{Al}_{2} \mathrm{O}_{3}-1.69 \mathrm{Fe}_{2} \mathrm{O}_{3}$

$\mathrm{C}_{4} \mathrm{AF}=3,04 \mathrm{Fe}_{2} \mathrm{O}_{3}$

$C$ libre $\quad=\mathrm{CaO}-\left(2,80 \mathrm{SiO}_{2}+1,65 \mathrm{Al}_{2} \mathrm{O}_{3}+0,35 \mathrm{Fe}_{2} \mathrm{O}_{3}\right)$

$$
\begin{gathered}
\text { SISTEMA } C-S-A-F \\
\left(C_{2} S-C_{3} A-C_{12} A_{7}-C_{4} A F\right) \\
\text { POBRE EN CAL } \\
\hline
\end{gathered}
$$

$$
\begin{aligned}
\mathrm{C}_{2} \mathrm{~S} & =2,87 \mathrm{SiO}_{2} \\
\mathrm{C}_{3} \mathrm{~A} & =3,61 \mathrm{CaO}-\left(6,75 \mathrm{SiO}_{2}+3.31 \mathrm{Al}_{2} \mathrm{O}_{3}+2.96 \mathrm{Fe}_{2} \mathrm{O}_{3}\right) \\
\mathrm{C}_{12} \mathrm{~A}_{7} \circ \mathrm{C}_{5} \mathrm{~A}_{3} & =4,88 \mathrm{SiO}_{2}+4.31 \mathrm{Al}_{2} \mathrm{O}_{3}+0.92 \mathrm{Fe}_{2} \mathrm{O}_{3}-2.61 \mathrm{CaO}
\end{aligned}
$$




\section{ENSAYO DE PUZOLANICIDAD, SEGUN FRATINI}

ALCALINIDAD TOTAL, MILIMOLES DE OH' POR LITRO

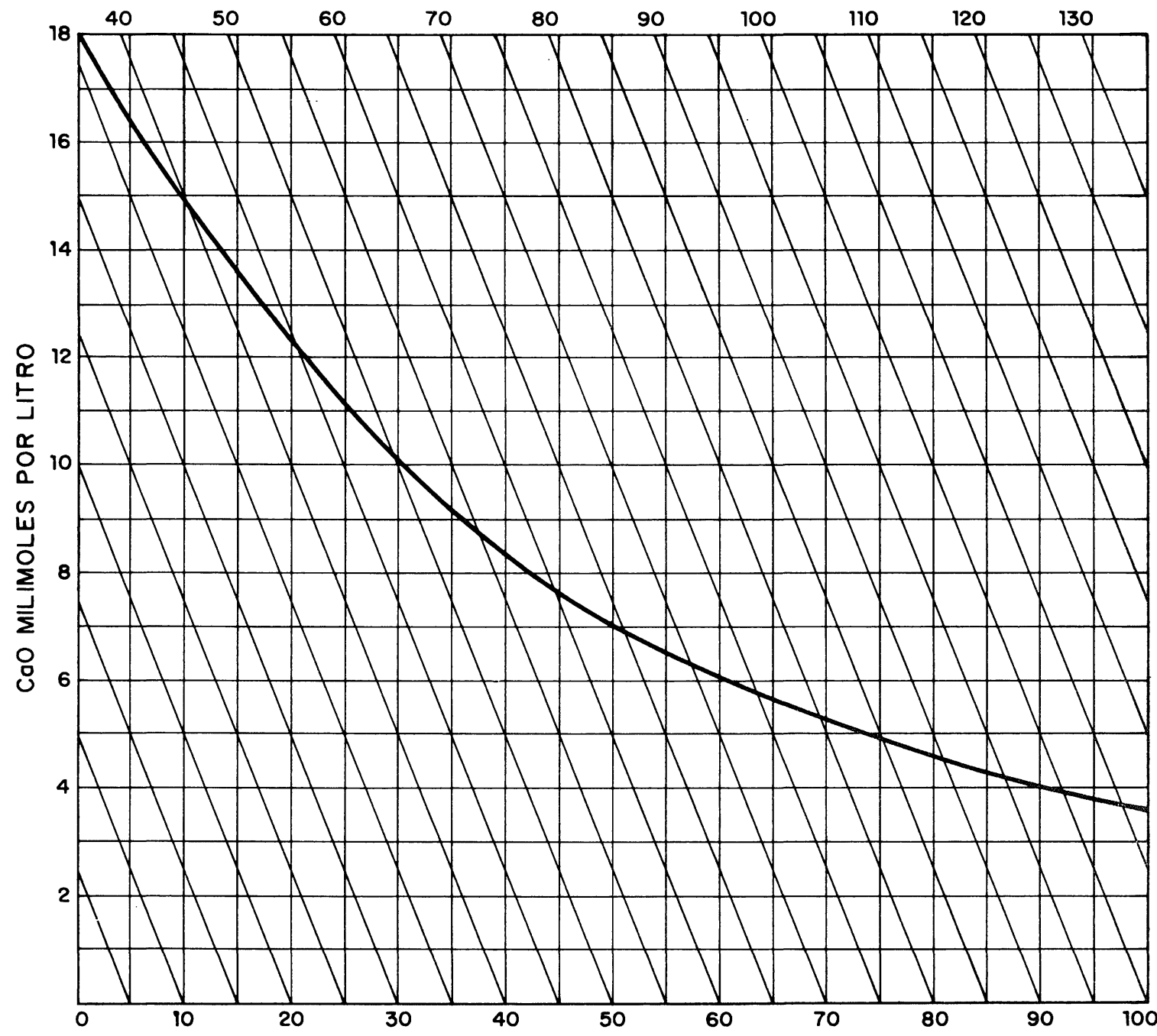

MILIMOLES DE OHTLITRO $\longrightarrow(\mathrm{KOH} Y \mathrm{NOOH})$ 


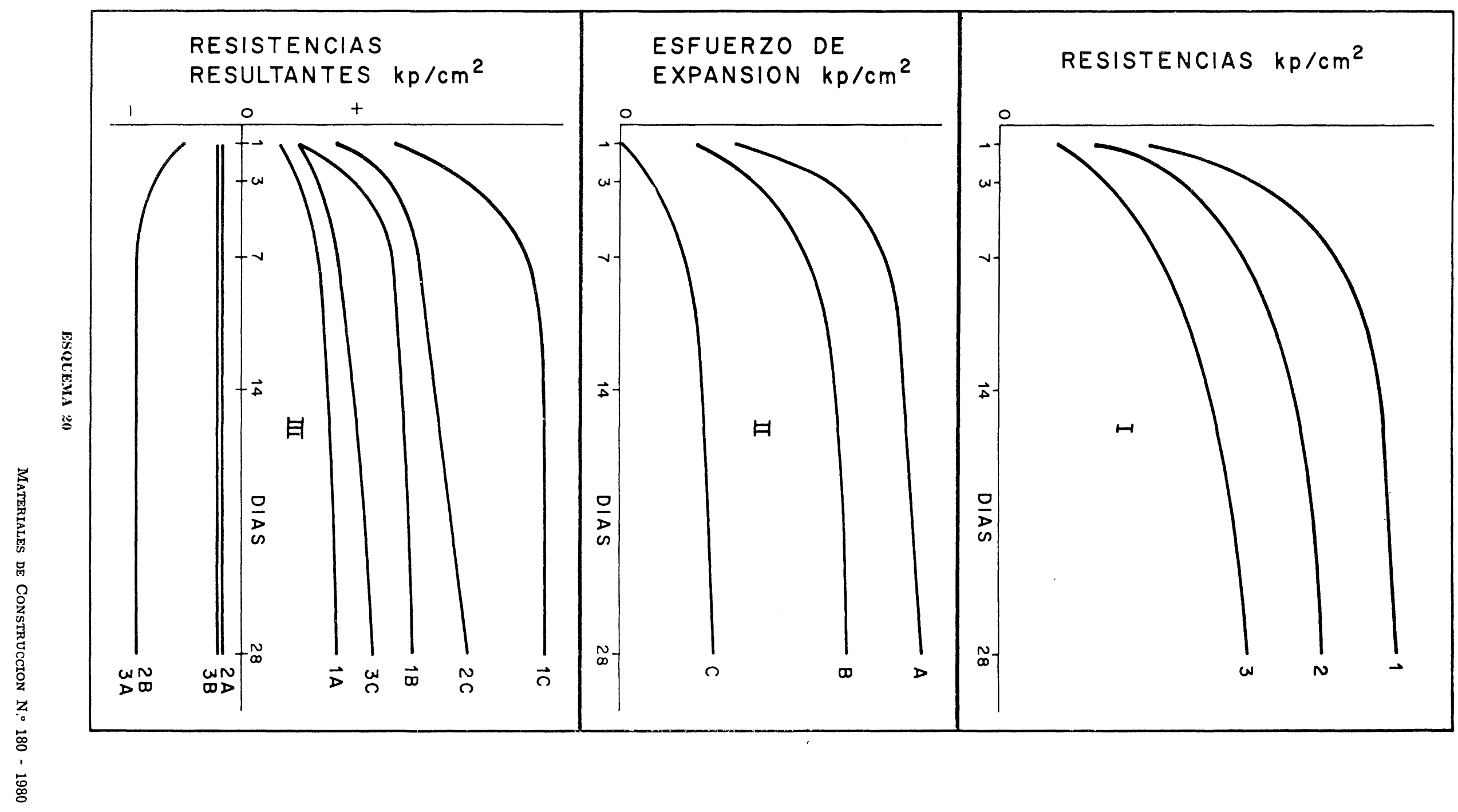




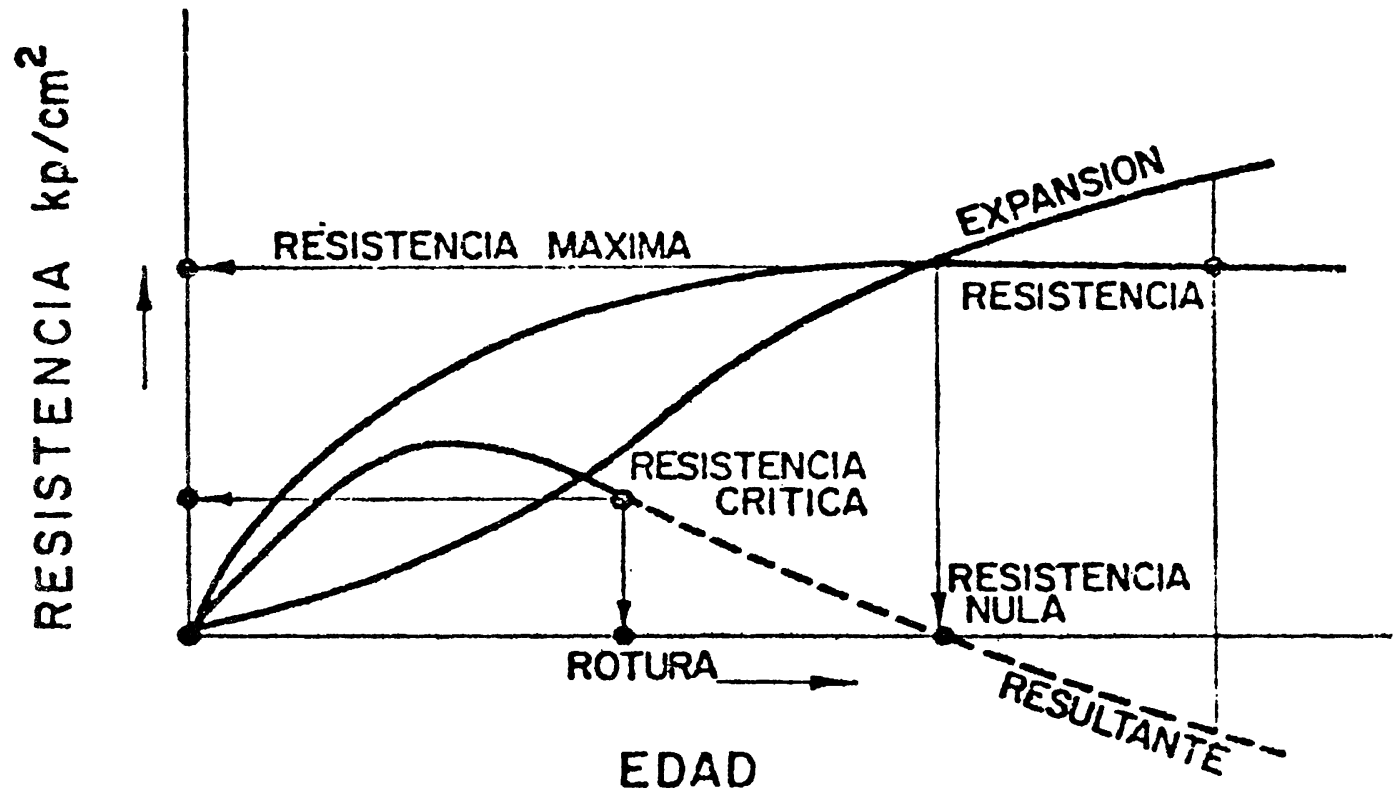

ESQUEMA 21

NORMAS, PRESCRIPCIONES Y ENSAYOS DE EXPANSION DE CEMENTOS

\begin{tabular}{|c|c|c|c|c|c|c|c|}
\hline \multirow{3}{*}{ PAISES } & \multirow{3}{*}{$\begin{array}{c}\text { NUMERO } \\
\text { DE } \\
\text { ENSAYOS }\end{array}$} & \multicolumn{5}{|c|}{ TIPOS DE ENSAYOS } & \multirow{3}{*}{$\begin{array}{c}\text { TOTAL } \\
\text { DE } \\
\text { ENSAYOS }\end{array}$} \\
\hline & & \multicolumn{2}{|c|}{ GALLETAS } & \multicolumn{2}{|c|}{ AGUJAS Le Châtelier } & \multirow{2}{*}{ AUTOCLAVE } & \\
\hline & & EN FRIO & EN CALIENTE & EN FRIO & EN CALIENTE & & \\
\hline$(59 \%)$ & & $(2 \%)$ & $(7 \%)$ & $(0 \%)$ & $(27 \%)$ & $(23 \%)$ & \\
\hline 26 & 1 & $\begin{array}{l}1 \\
(1 \%)\end{array}$ & $\begin{array}{l}3 \\
(4 \%)\end{array}$ & $\begin{array}{l}0 \\
(0 \%)\end{array}$ & $\begin{array}{l}12 \\
(18 \%)\end{array}$ & $\begin{array}{l}10 \\
(15 \%)\end{array}$ & $\begin{array}{l}26 \\
(38 \%)\end{array}$ \\
\hline (27\%) & & $(7 \%)$ & $(9 \%)$ & $(1 \%)$ & $(7 \%)$ & $(3 \%)$ & \\
\hline 12 & 2 & $\begin{array}{l}6 \\
(9 \%)\end{array}$ & $\begin{array}{l}8 \\
(12 \%)\end{array}$ & 1 & $\begin{array}{l}6 \\
(9 \%)\end{array}$ & $\begin{array}{l}3 \\
(4 \%)\end{array}$ & $\begin{array}{ll}24 & \\
& (35 \%)\end{array}$ \\
\hline$(14 \%)$ & & $(3 \%)$ & $(3 \%)$ & $(0 \%)$ & $(5 \%)$ & $(3 \%)$ & \\
\hline 6 & 3 & $\begin{array}{l}4 \\
(6 \%)\end{array}$ & $\begin{array}{l}4 \\
(6 \%)\end{array}$ & $\begin{array}{l}0 \\
(0 \%)\end{array}$ & $\begin{array}{l}6 \\
(9 \%)\end{array}$ & $\begin{array}{l}4 \\
(6 \%)\end{array}$ & $\begin{array}{l}18 \\
(27 \%)\end{array}$ \\
\hline$(100 \%)$ & & $(12 \%)$ & $(19 \%)$ & $(1 \%)$ & $(39 \%)$ & $(29 \%)$ & \\
\hline 44 & $\begin{array}{l}1,2,3 \\
(0 \text { más ) }\end{array}$ & $\begin{array}{l}11 \\
(16 \%)\end{array}$ & $\begin{array}{l}15 \\
(22 \%)\end{array}$ & ${ }^{1}(1 \%)$ & $\begin{array}{l}24 \\
(36 \%)\end{array}$ & $\begin{array}{l}17 \\
25 \%)\end{array}$ & $\begin{array}{l}68 \\
(100 \%)\end{array}$ \\
\hline
\end{tabular}


ENSAYO DE EXPANSION CON AGUJAS Le Châtelier

\begin{tabular}{|c|c|c|c|c|c|c|c|c|c|c|c|}
\hline \multicolumn{4}{|c|}{ EN FRIO } & \multicolumn{8}{|c|}{ EN CALIENTE } \\
\hline \multicolumn{2}{|c|}{$\begin{array}{l}\text { Tiempo de } \\
\text { tratamiento }\end{array}$} & \multicolumn{2}{|c|}{ Expansión (mm) } & \multicolumn{2}{|c|}{$\begin{array}{l}\text { Tiempo de } \\
\text { tratomiento }\end{array}$} & \multicolumn{2}{|c|}{ Expansión $(\mathrm{mm})$} & \multicolumn{2}{|c|}{$\begin{array}{l}\text { Tiempo de } \\
\text { aireación }\end{array}$} & \multicolumn{2}{|c|}{ Expansión (mm) } \\
\hline minimo & maximo & minima & máxima & minimo & máximo & mínima & máxima & minimo & máximo & minima & móximo \\
\hline - & - & 一 & 一 & 1 hora & 6 horas & $3 \mathrm{~mm}$ & $10 \mathrm{~mm}$ & I dia & 7 dias & $2.5 \mathrm{~mm}$ & $5 \mathrm{~mm}$ \\
\hline \multicolumn{2}{|c|}{7 dias } & - & $3 \mathrm{~mm}$ & I hora & 6 horas & $5 \mathrm{~mm}$ & $10 \mathrm{~mm}$ & 3 dias & 7 dias & - & $5 \mathrm{~mm}$ \\
\hline 一 & - & - & 一 & 1 hora & 3 horas & $5 \mathrm{~mm}$ & $10 \mathrm{~mm}$ & - & 7 dias & - & $5 \mathrm{~mm}$ \\
\hline \multicolumn{12}{|c|}{ VALORES MEDIOS } \\
\hline \multicolumn{2}{|c|}{7 dias } & \multicolumn{2}{|c|}{$3 \mathrm{~mm}$} & \multicolumn{2}{|c|}{3 horas } & \multicolumn{2}{|c|}{$7.5 \mathrm{~mm}$} & \multicolumn{2}{|c|}{5 dias } & \multicolumn{2}{|c|}{$5 \mathrm{~mm}$} \\
\hline \multicolumn{12}{|c|}{ VALORES DRASTICOS } \\
\hline \multicolumn{2}{|c|}{ - } & \multicolumn{2}{|c|}{ 一 } & \multicolumn{2}{|c|}{6 horas } & \multicolumn{2}{|c|}{$3 \mathrm{~mm}$} & \multicolumn{2}{|c|}{1 dia } & \multicolumn{2}{|c|}{$2.5 \mathrm{~mm}$} \\
\hline \multicolumn{12}{|c|}{ VALORES MENOS DRASTICOS } \\
\hline \multicolumn{2}{|c|}{-} & \multicolumn{2}{|c|}{-} & \multicolumn{2}{|c|}{ I hora } & \multicolumn{2}{|c|}{$10 \mathrm{~mm}$} & \multicolumn{2}{|c|}{7 dios } & \multicolumn{2}{|c|}{$5 \mathrm{~mm}$} \\
\hline
\end{tabular}

ESQUEMA 23

\section{ALUMINATOS HIDRATADOS COMPLEJOS}

$$
\begin{array}{r}
\mathrm{C}_{3} \mathrm{~A}+3 \mathrm{CaSO}_{4}+31 \mathrm{H}_{2} \mathrm{O} \rightarrow \mathrm{C}_{3} \mathrm{~A} .3 \mathrm{CaSO}_{4} \cdot 31 \mathrm{H}_{2} \mathrm{O} \\
\text { ETTRINGITA }
\end{array}
$$

$$
\begin{aligned}
& \mathrm{C}_{3} \mathrm{~A}+\mathrm{CaSO}_{4}+12 \mathrm{H}_{2} \mathrm{O} \longrightarrow \mathrm{C}_{3} \mathrm{~A} \mathrm{CaSO}_{4} \cdot 12 \mathrm{H}_{2} \mathrm{O} \\
& \text { MONOSULFOALUMINATO }
\end{aligned}
$$

$$
\begin{aligned}
\mathrm{C}_{3} \mathrm{~A}+\mathrm{CaCl}_{2}+8 \mathrm{H}_{2} \mathrm{O} \longrightarrow & \mathrm{C}_{3} \mathrm{~A} \cdot \mathrm{CaCl}_{2} \cdot 10 \mathrm{H}_{2} \mathrm{O} \\
& \text { SAL DE FRIEDEL }
\end{aligned}
$$


NORMAS ASTM

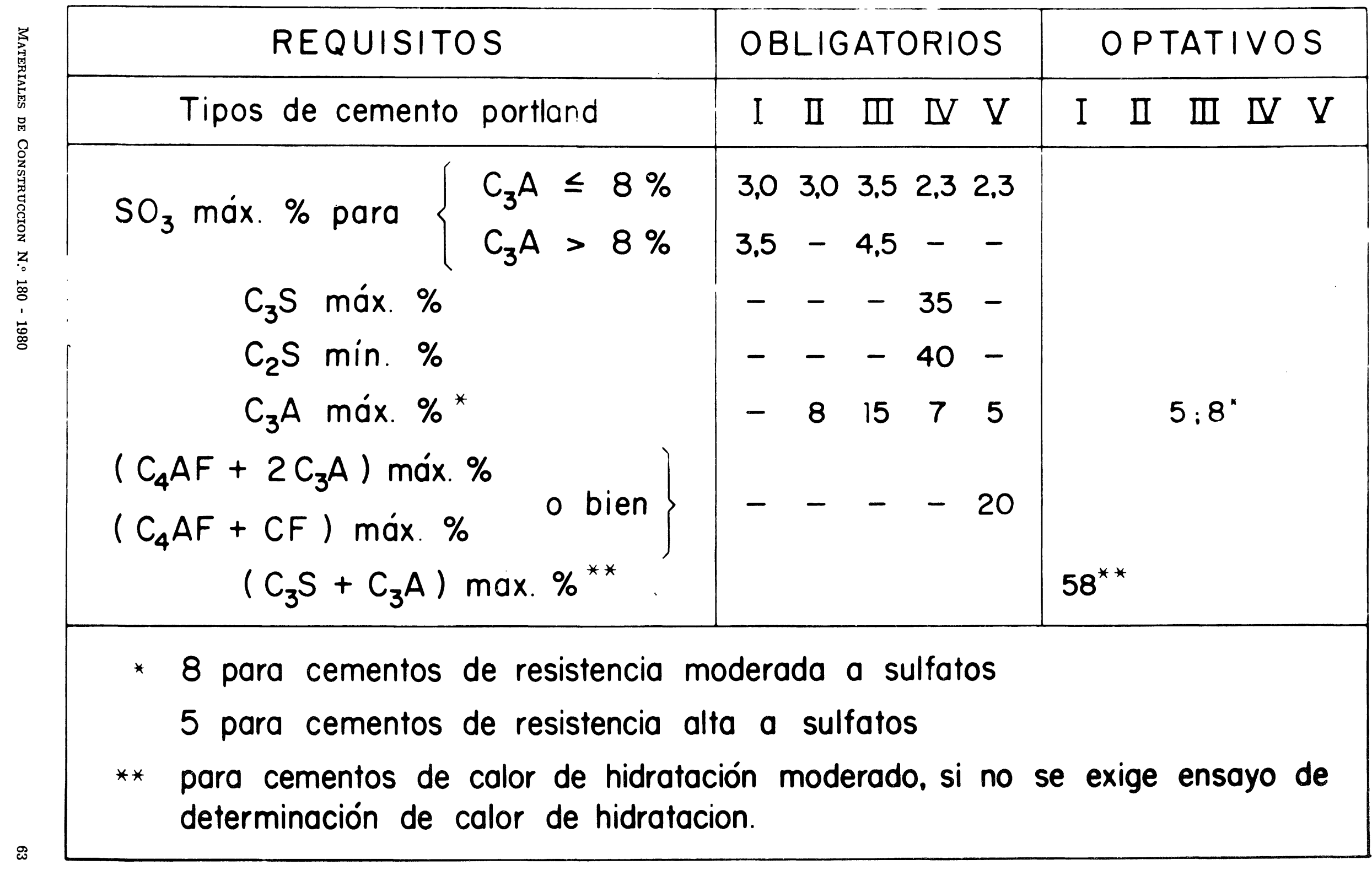




\section{COMPOSICION DE ESCORIAS SIDERURGICAS}

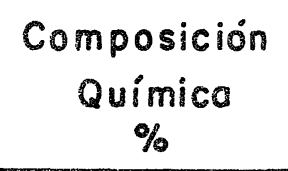

ESQUEMA $: 6$ 


\title{
INDICES DE ESCORIAS SIDERURGICAS PARA CEMENTOS DE HORNO ALTO
}

\author{
Indices \\ Valores \\ Químicos \\ Mínimos Medios \\ Máximos \\ $\mathrm{C} / \mathrm{s}$ \\ 0,9 \\ 1,35 \\ 1,6 \\ $C+M / S$ \\ 1,0 \\ 1,45 \\ 1,8 \\ $C+M / S+A$ \\ 0,75 \\ 1,0 \\ 1,35 \\ $C+M+1 / 3 A / S+2 / 3 A>1$ \\ $C+M+A / S$ \\ $>1$ \\ 0,9 \\ 1,25 \\ 1,65 \\ 1,45 \\ 1,9 \\ 2,35 \\ 1,15 \\ 1,8 \\ $1,5-1,9^{*}$ \\ 2,35 \\ 15,5 \\ $12-16^{*}$ \\ 28 \\ $C+M+(A-10 \%) / S+10 \%>1$ \\ $\operatorname{CaS}+C+1 / 2 M+A / S+\bar{M}+\bar{F}>1,9^{* *}$ \\ $\mathrm{C} / 56 / 1,5 \mathrm{~S} / 60+3,0 \mathrm{~A} / 102>0,81^{* * * *}$ \\ * : Intervalos óptimos \\ ** : Condición óptima \\ *** : Condición buena \\ ****: Condición especial para cementos resistentes \\ a ataques químicos por aguas y terrenos yesíferos \\ $S=\mathrm{SiO}_{2} ; A=\mathrm{Al}_{2} \mathrm{O}_{3} ; \mathrm{F}=\mathrm{Fe}_{2} \mathrm{O}_{3} ; \mathrm{C}=\mathrm{CaO} ; \mathrm{M}=\mathrm{MgO} ; \bar{M}=\mathrm{MnO}$
}

ESQLEMA 2i 


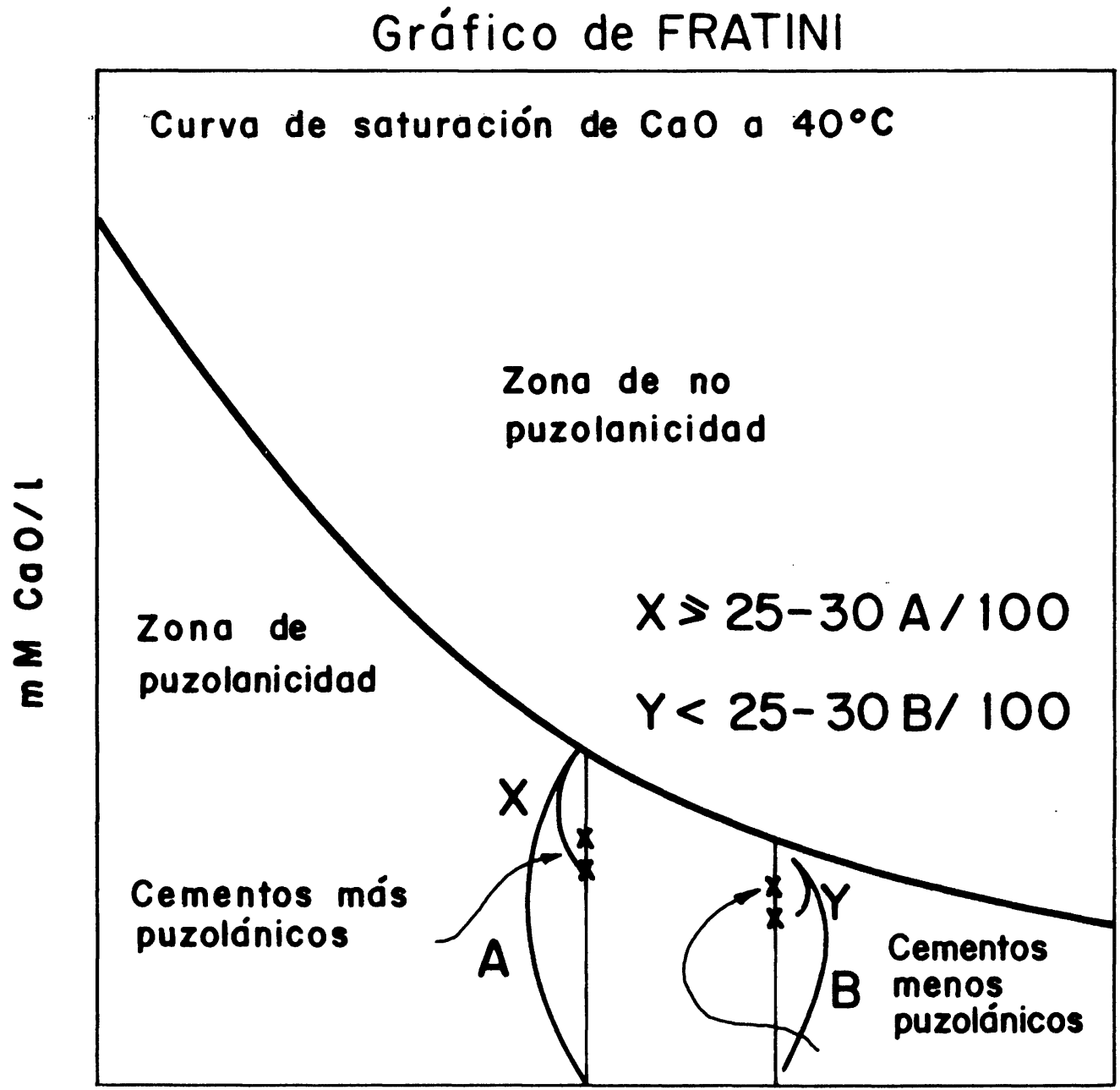

$m M \mathrm{OH}^{-} / \mathrm{I}$

ESQUEMA 28 


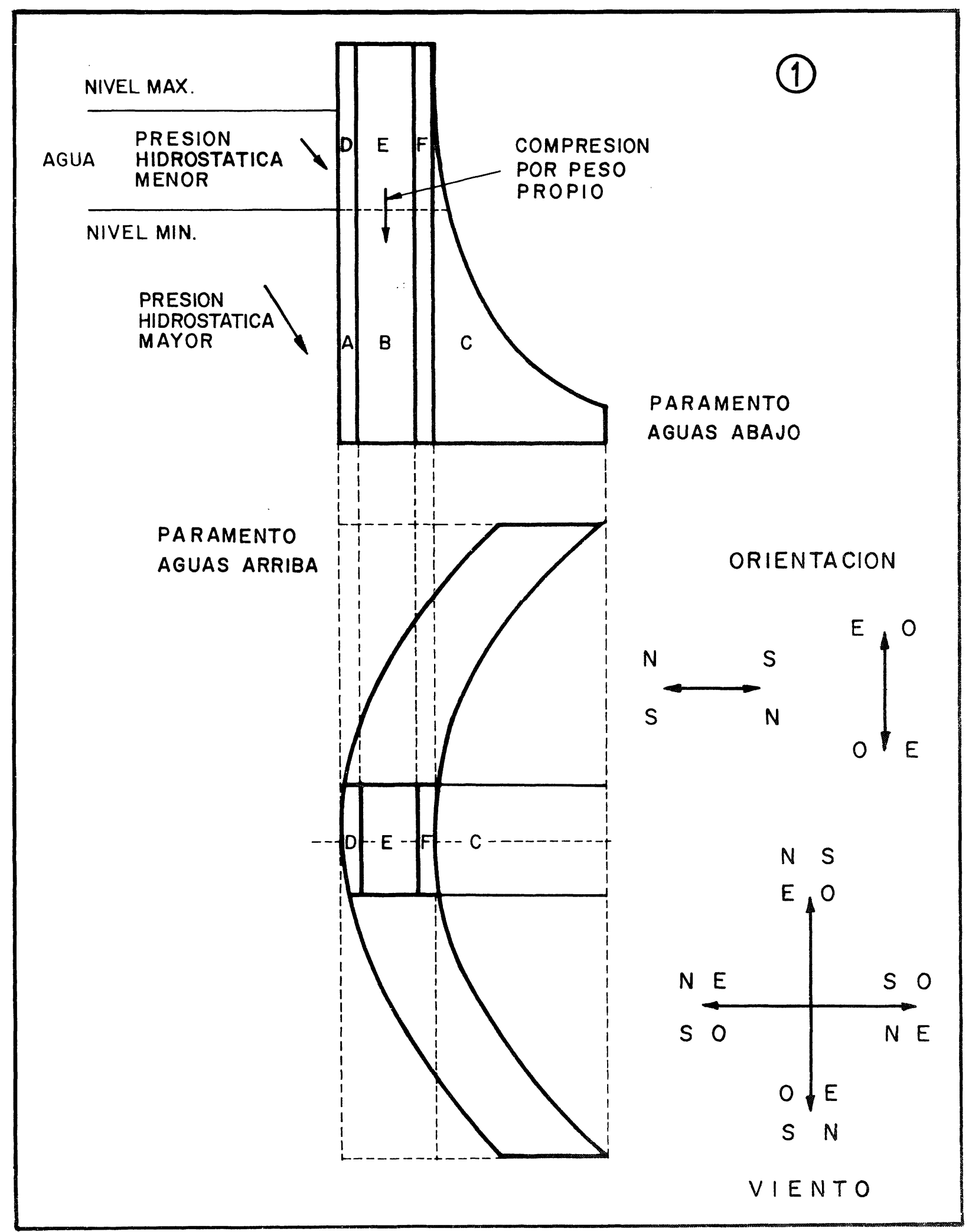

ESQLEMA 


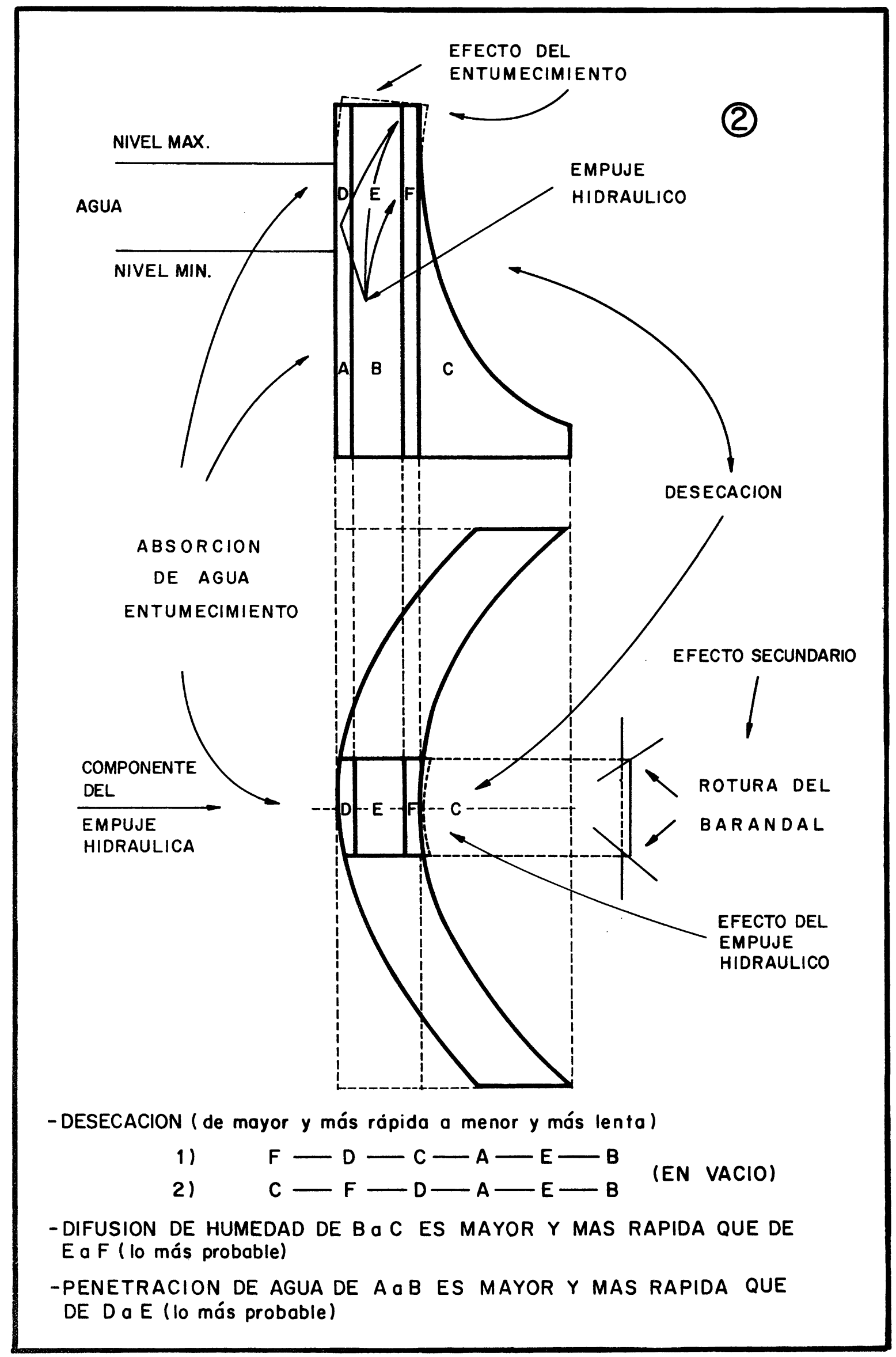

ESQLENA 30 


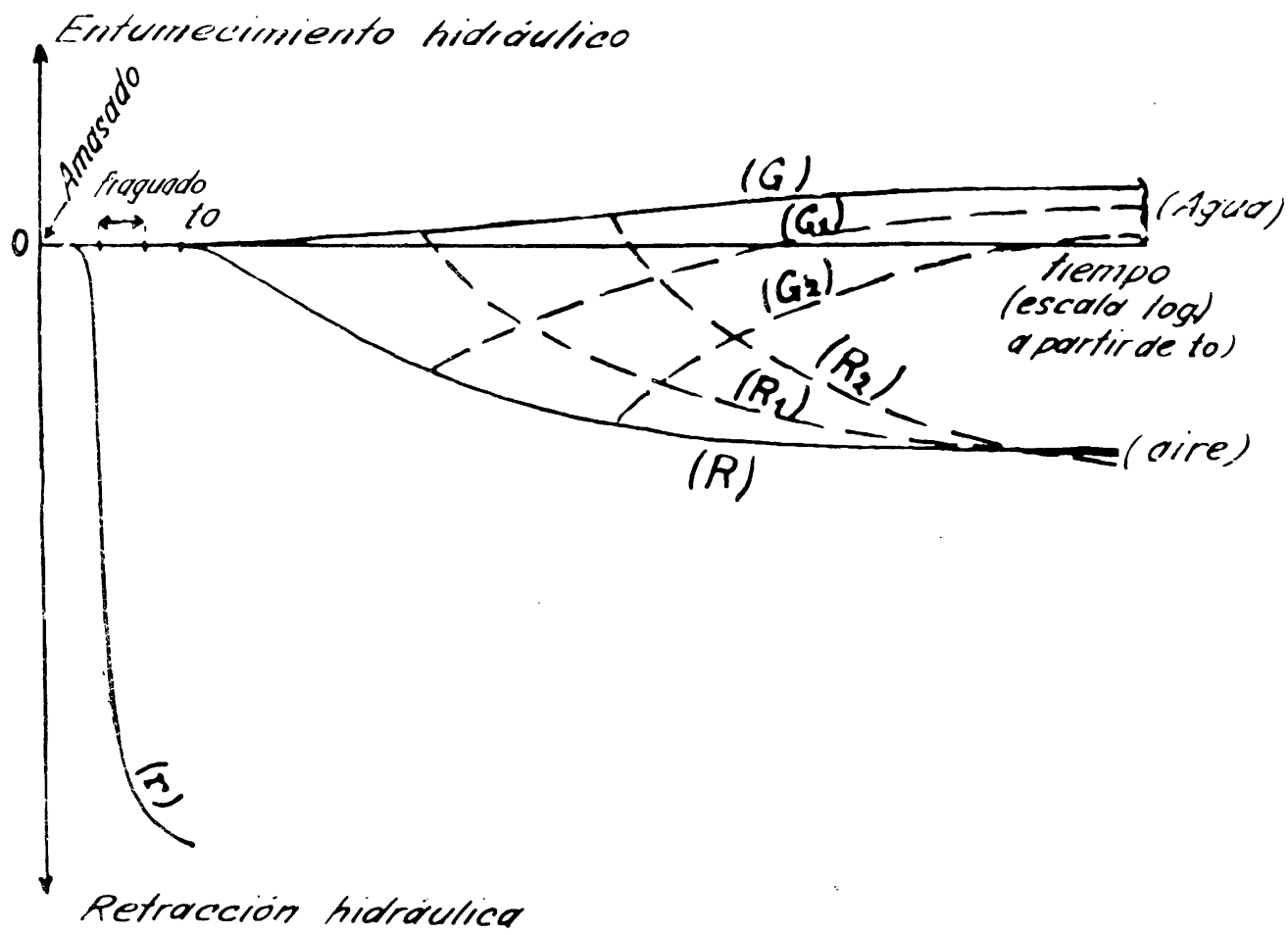

ENQLEMA 31

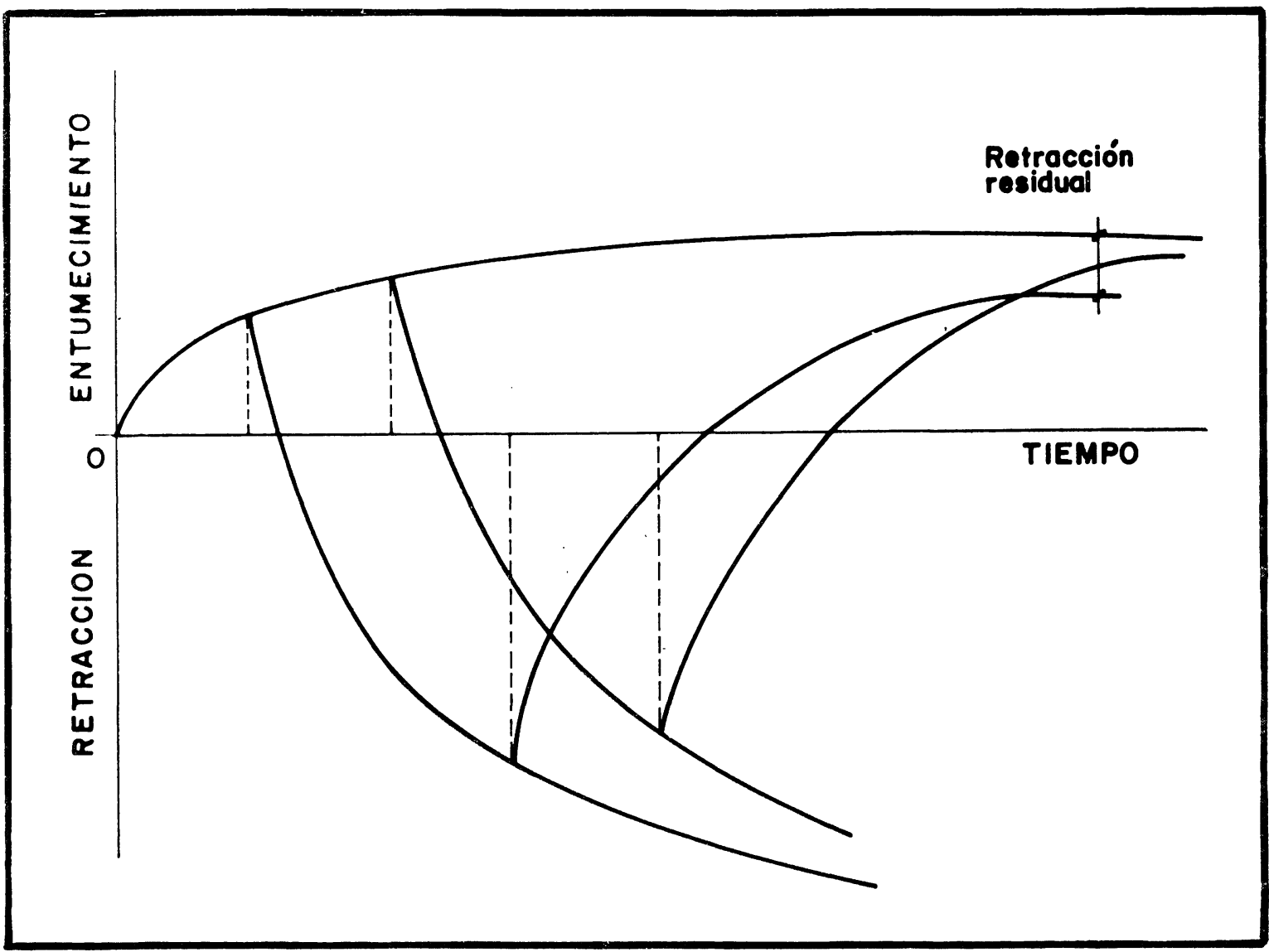

ESQCEMA 31 bis 


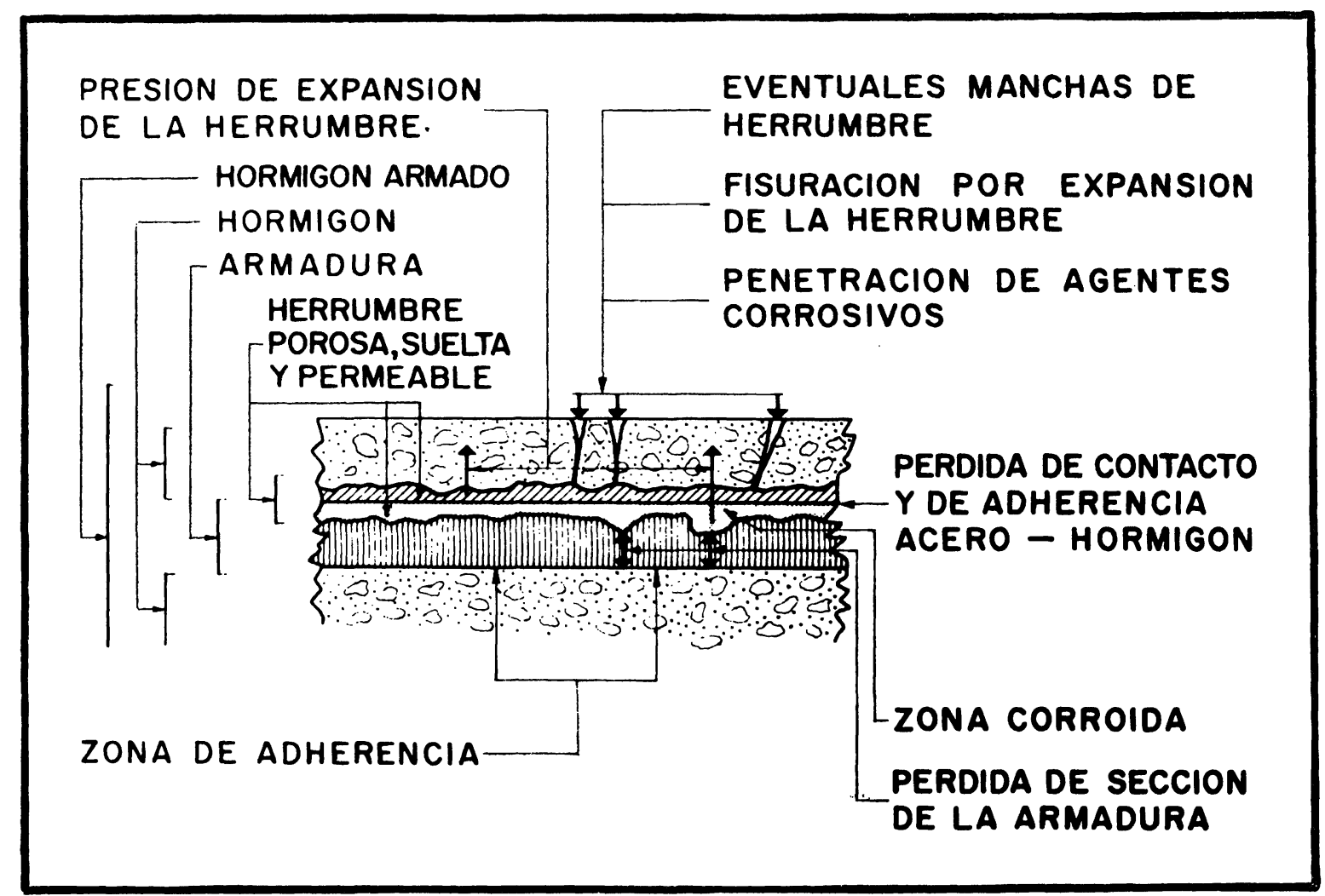

ESQLEMA 32 


\section{ROSIN-RAMMLER-SPERLING}

\section{(BENNET)}

$$
\begin{gathered}
P=100\left(1-e^{-b x^{n}}\right) \\
R=100 e^{-b x^{n}}
\end{gathered}
$$

$\log (\log 100 / R)=n \cdot \log x+C$

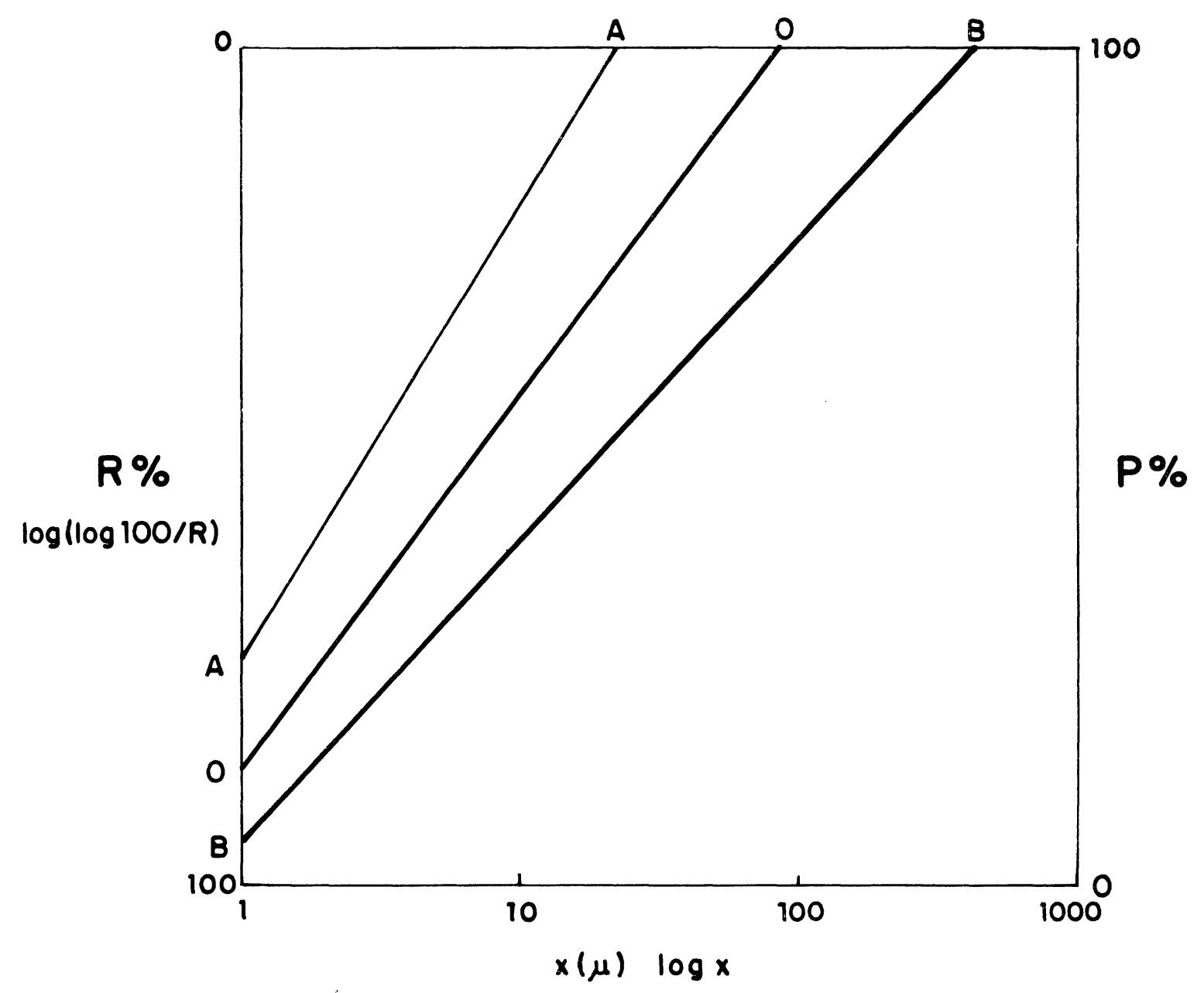

$A A$ más fino que 00 más fino que $B B$

ESCLE.MA 33 

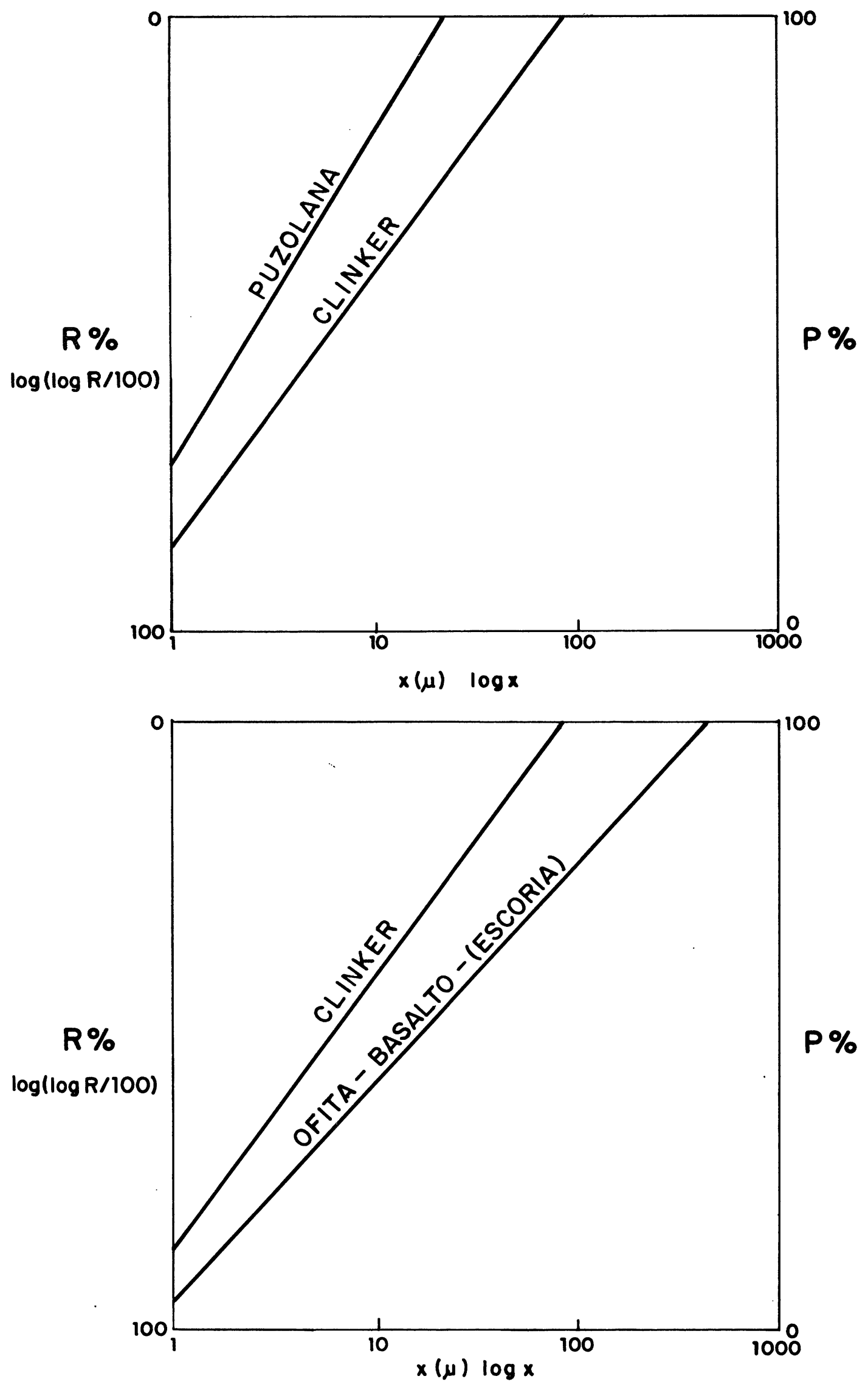

ESQLFMA 34 


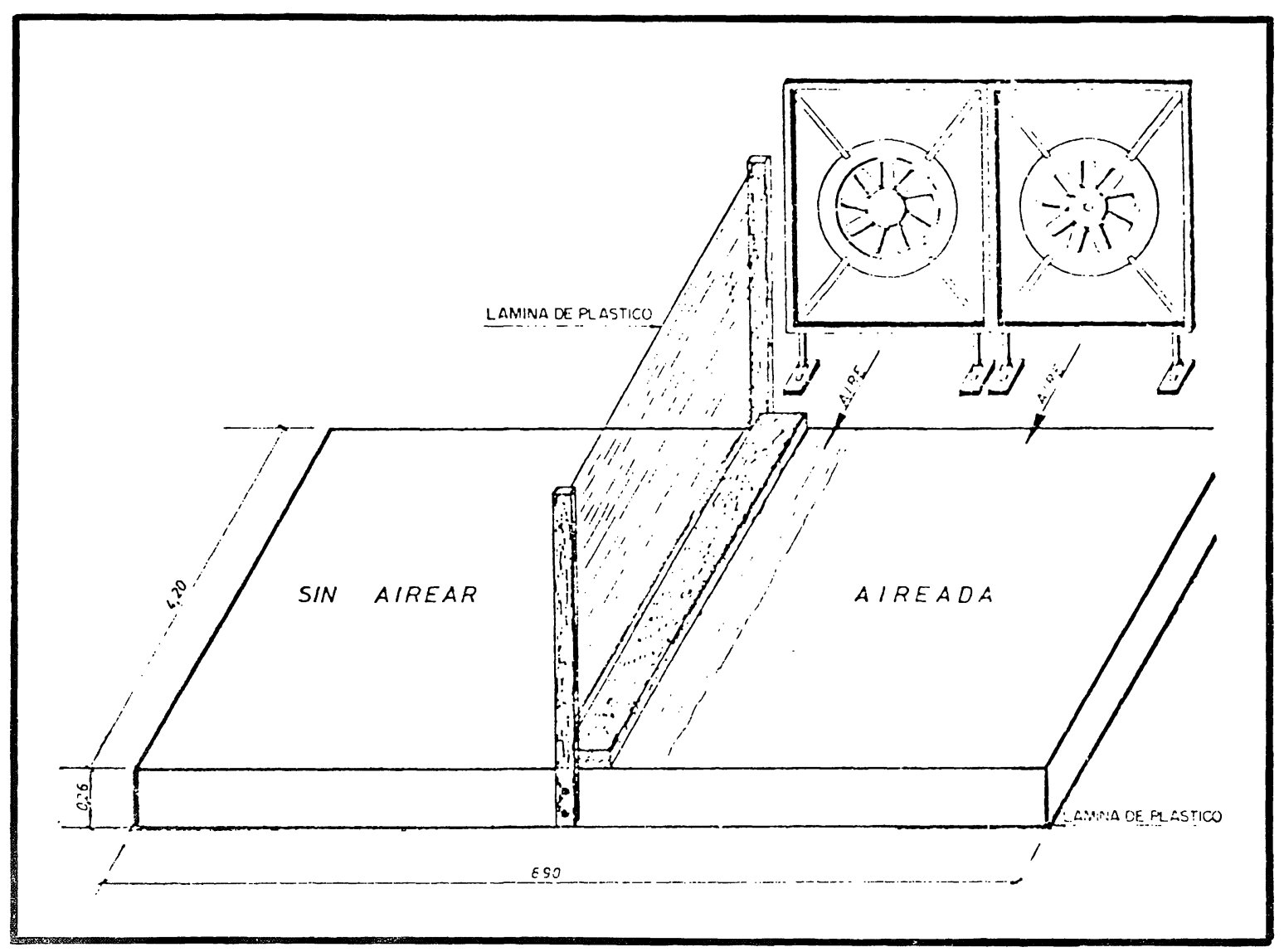

ESQUEMA 3i

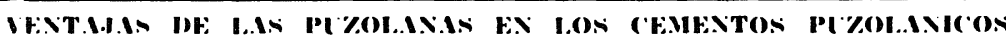

A. En las resistencias mecinicas

A.1. A largo plazo. al prolongar el periodo de endurecimiento :

A.1.1. A traccion:

A.1.2. A compresion:

A.1.3. Mejor relacion traccion compresion:

B. En la estabilidad

B.1. Frente a la expansion por cal libre:

B.2. Frente a la expansion por sulfatos:

B.3. Frente a la expansion por reaceion aridoalcalis:

3.4. Frente a la retraceion hidratulica de secatdo. por la menor relacion a c

3.5. Frente a la retraceion termical por enfriamiento:

B3.6. Frente a la fisuracion:

C. En la durabilidad

c.1. Frente a ataques por aguas puras $y$ acidats:

C'.2. Frente a alaques por aguats y suelos selomitosos:

('.3. Jremle a alaques por aguat de mar:

c t. Fremte a allaques por gatses de descomposicenter formentacion de materias orgatMicis: :

('.j. Frente a la desintegraciom por reaceion arido-alcalis :
D. En la plasticidad

D.1. Rebajando la relación a $\mathrm{c}$ :

D.2. Reduciendo la segregación:

D.3. Evitando la exudación y el rezumado:

E. En la impermeabilidad

E.1. Reduciendo la porosidad:

E.2. Evitando la formación de eflorescencias:

E.3. Produciendo mayor cantidad de tobermorita:

F. En la adherencia

F.1. Del arido a la pasta:

F'.2. Del mortero a las armaduras:

G. En il comportamiento térmico

(i.1. Al desprender menor calor de hidrataci(in):

G.2. Al producir menor elevacion de temperatura:

H. En rl rendimiento y e'n la e'conomia

H.1. Al corresponder a los cementos puzolatnicos mayor volumen que a otros conglomerantes a igualdad de peso:

H.2. Al ser los cementos puzolianicos. en general. conglomerantes mas baratos. 


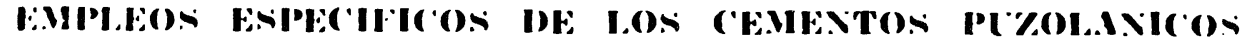

a) Macizos de hormigón en grandes masas (presas):

b) Cimentaciones en todo terreno:

c) Obras maritimas:

d) Obras sanitarias:

e) Albañileria (fibricas de ladrillo y mamposteria):

f) Enfoscados:

(g) Solados:

h) Baldosines hidriulicos:

i) Prefabricados de elementos estructurales de hormigon armado o sin armar. especialmente curados por tratamientcs termicos:

j) Hormigones especiales confeccionados en central. 